Article

\title{
Depolarization Ratio Profiles Calibration and Observations of Aerosol and Cloud in the Tibetan Plateau Based on Polarization Raman Lidar
}

\author{
Guangyao Dai ${ }^{1}$, Songhua $\mathrm{Wu}^{1,2, *(1)}$ and Xiaoquan Song ${ }^{1,2}$ (1) \\ 1 Ocean Remote Sensing Institute, Ocean University of China, Qingdao 266100, China; \\ dgy1105@163.com (G.D.); songxq@ouc.edu.cn (X.S.) \\ 2 Laboratory for Regional Oceanography and Numerical Modeling, Qingdao National Laboratory for Marine \\ Science and Technology, Qingdao 266237, China \\ * Correspondence: wush@ouc.edu.cn; Tel.: +86-532-6678-2573
}

Received: 4 January 2018; Accepted: 22 February 2018; Published: 1 March 2018

\begin{abstract}
A brief description of the Water vapor, Cloud and Aerosol Lidar (WACAL) system is provided. To calibrate the volume linear depolarization ratio, the concept of " $\Delta 90^{\circ}$-calibration" is applied in this study. This effective and accurate calibration method is adjusted according to the design of WACAL. Error calculations and analysis of the gain ratio, calibrated volume linear depolarization ratio and particle linear depolarization ratio are provided as well. In this method, the influences of the gain ratio, the rotation angle of the plane of polarization and the polarizing beam splitter are discussed in depth. Two groups of measurements with half wave plate (HWP) at angles of $\left(0^{\circ}, 45^{\circ}\right)$ and $\left(22.5^{\circ},-22.5^{\circ}\right)$ are operated to calibrate the volume linear depolarization ratio. Then, the particle linear depolarization ratios measured by WACAL and CALIOP (the Cloud-Aerosol Lidar with Orthogonal Polarization) during the simultaneous observations were compared. Good agreements are found. The calibration method was applied in the third Tibetan Plateau Experiment of Atmospheric Sciences (TIPEX III) in 2013 and 2014 in China. Vertical profiles of the particle depolarization ratio of clouds and aerosol in the Tibetan Plateau were measured with WACAL in Litang $\left(30.03^{\circ} \mathrm{N}, 100.28^{\circ} \mathrm{E}, 3949 \mathrm{~m}\right.$ above sea level (a.s.l.)) in 2013 and $\mathrm{Naqu}\left(31.48^{\circ} \mathrm{N}, 92.06^{\circ} \mathrm{E}, 4508 \mathrm{~m}\right.$ a.s.1.) in 2014. Then an analysis on the polarizing properties of the aerosol, clouds and cirrus over the Tibetan Plateau is provided. The particle depolarization ratio of cirrus clouds varies from 0.36 to 0.52 , with a mean value of $0.44 \pm 0.04$. Cirrus clouds occurred between 5.2 and $12 \mathrm{~km}$ above ground level (a.g.l.). The cloud thickness ranges from 0.12 to $2.55 \mathrm{~km}$ with a mean thickness of $1.22 \pm 0.70 \mathrm{~km}$. It is found that the particle depolarization ratio of cirrus clouds become larger as the height increases. However, the increase rate of the particle depolarization ratio becomes smaller as the height increases.
\end{abstract}

Keywords: depolarization ratio calibration; polarization Raman lidar; the Tibetan Plateau; cloud and aerosol; cirrus

\section{Introduction}

As a significant branch in the field of lidar, polarization lidar plays an important role in the detection of spatial and temporal distribution of aerosols and clouds. It is a well-established technique to measure the profile of the physical properties of clouds [1,2] and aerosol [3-5]. Typically, polarization lidars use a linearly polarized laser and are equipped with a receiver that can separately measure the components of the return signal polarized perpendicular and parallel to the outgoing beam. The calibrated ratio of these two components is defined as depolarization ratio. Polarization-sensitive lidars have proven to be highly effective in discriminating spherical and nonspherical particles in the atmosphere. They are applied to distinguish ice clouds from water clouds and to identify layers with 
ice crystals in mixed-phase clouds [6-8]. With polarization lidar measurements, the depolarization ratios of cirrus cloud are investigated. Sassen and Benson (2001) studied the midlatitude cirrus clouds by using $694 \mathrm{~nm}$ polarization lidar and they found the depolarization ratios of cirrus display a steady increase with height [9]. Chen et al. (2002) performed the depolarization ratio measurements in Taiwan and they reported that the depolarization ratios of cirrus increase from approximately 0.2 to 0.5 in the height range of $11-15 \mathrm{~km}$ and are smaller than 0.3 between 16 and $17 \mathrm{~km}$ [10]. Sunilkumar and Parameswaran (2005) measured tropical cirrus properties and they found the linear depolarization ratio within the clouds shows a small increase with decrease in temperature [11]. Polarization lidar can also be used to do aerosol profiling [4,5,12-14] and help to classify desert dust from other aerosols such as biomass burning aerosols, fresh smoke, and so forth. Gobbi et al. (2000) classified six particle types using depolarization ratio during the Saharan dust event observations in Crete [15]. Sakai et al. (2002) reported a simple model of aerosol mixture based on the particle depolarization ratio and the Ångström exponent of aerosol backscatter coefficient [16]. Murayama et al. (2004) observed Asian dust and Siberian smoke with multiwavelength polarization Raman lidar and large particle depolarization ratio difference between dust and smoke is found [17]. For better understanding of the spectral dependence of the dust and smoke linear depolarization ratio on the size distribution, dual-wavelength aerosol polarization lidar [17-19] and triple-wavelength aerosol polarization lidar are established [20,21]. With depolarization ratio, lidar ratio, Ångström exponent and other intensive optical properties of particles, the cloud phase, dust, smoke, urban, maritime and other types of aerosol are classified [22-25]. In May 2006, the spaceborne Cloud-Aerosol Lidar with Orthogonal Polarization (CALIOP) that performs global profiling of aerosols and clouds in the troposphere and lower stratosphere launched. CALIOP provides several optical properties of aerosol and clouds such as backscatter coefficient, particle linear depolarization ratio and color ratio. The global dataset allows a new view on earth's atmosphere. Algorithms based on integrated attenuated backscatter and depolarization ratio have been developed to classify aerosol and cloud [26].

In some papers, the linear depolarization ratio is defined as the ratio of the cross-polarized channel to the total channel $[16,27]$. In the following text, the volume linear depolarization ratio is defined as the ratio of the cross-polarized to the parallel-polarized backscattered signal [28]. The particle linear depolarization ratio is defined as the ratio of the perpendicular polarization component to the parallel component of aerosol (without molecular part) scattering [12,29,30]. The planes of polarization of the two employed detectors are parallel and orthogonal to the plane of polarization of the transmitted linearly polarized laser. The accurate measurement of depolarization ratio depends on the determination of the system calibration constants including gain ratio, offset angle, cross-talk of polarizing beam splitter (PBS). Thus it needs careful calibration. In previous works, the Rayleigh calibration method was applied within the data analysis by assuming pure Rayleigh depolarization in an aerosol-free height range [8,31,32]. Reichardt et al. (2003) presented a three-signal method for calibration of depolarization ratio. This method is applied to polar stratospheric cloud observations [33]. In 2005, Alvarez et al. used a rotatable half-wave plate inserted into the optical path of the lidar receiver to obtain the system calibration constants of gain ratio and offset angle. The operational details of the technique were illustrated in the First International Satellite Cloud Climatology Project Regional Experiment of LaRC, NASA [34]. In his work, by using a secondary PBS, the polarization purity of the perpendicular channel is assumed to be ensured. Therefore, the influence resulting from cross-talk of PBS are not discussed in detail. In 2009, Freudenthaler et al. described one accurate calibration method called " $\pm 45^{\circ}$-calibration" (developed to $\Delta 90^{\circ}$-calibration method [35]), which solved the effect of PBS and gain ratio [28]. In 2016, Bravo-Aranda et al. assessed lidar depolarization uncertainty by means of a polarimetric lidar simulator [36].

To conclude, it should be emphasized that, considering the actual lidar optical setup and measurement, the gain ratio, offset angle and the cross-talk of PBS are equally significant and need to be carefully calibrated. In the current paper, the existing " $\Delta 90^{\circ}$-calibration method" is modified to fit the WAter vapor, Cloud and Aerosol Lidar (WACAL). 
With a well calibrated polarization lidar, aerosol and clouds can be detected. In the current paper, Section 2 presents the WACAL system and the volume depolarization ratio calibration method. In Section 3, the results and an error analysis are provided. To cross check the calibrated depolarization ratio, the simultaneous measurements of particle depolarization ratio with WACAL and the Cloud-Aerosol Lidar with Orthogonal Polarization (CALIOP) were operated. The results are given as well in Section 3.

In Section 4, the application of the calibration method in the third Tibetan Plateau Experiment of Atmospheric Sciences (TIPEX III) in 2013 and 2014 in China is provided. The Tibetan Plateau is a vast elevated plateau in the middle of the Eurasian Continent with an average elevation above $4500 \mathrm{~m}$ above sea level, and has important roles in global and regional climate system [37]. It lies at a critical and sensitive junction of four climatic systems: the Westerlies, the East Asian Monsoon, the Siberian cold polar airflow and the Indian monsoon. Consequently, the assessment of the cloud and aerosol over the Tibetan Plateau is crucial. By means of this calibration method, the volume and particle depolarization ratios measured in the Tibetan Plateau are calibrated. The polarizing properties of clouds, aerosol and cirrus clouds are presented in Section 4.

\section{WACAL Lidar System and Depolarization Ratio Calibration}

\subsection{Optical Setup}

A three-wavelength combined elastic-backscatter Raman lidar, Water vapor, cloud and aerosol lidar (WACAL) is established to perform continuous observations of aerosol, clouds and water vapor. The system is based on the second and third harmonic frequency of a compact, pulsed Nd:YAG laser, which emits pulses of 400, 120 and $710 \mathrm{~mJ}$ output energy at wavelengths of 355, 532 and $1064 \mathrm{~nm}$, respectively, at a $30 \mathrm{~Hz}$ repetition rate. The optical receiver consists of four $308 \mathrm{~mm}$ diameter Newtonian telescopes. Five Hamamatsu 10721P-110 photomultipliers tubes (PMT) and one Hamamatsu G8931-20 APD are used to detect the lidar signals at wavelengths of 355, 387, 407, 532 (parallel-polarized), 532 (cross-polarized) and $1064 \mathrm{~nm}$. The acquisition system employs a six-channel LICEL transient recorder including analog and photon counting modes. The vertical resolution of the signal is $3.75 \mathrm{~m}$ and the temporal resolution is $16 \mathrm{~s}$. The details of WACAL are reported by Wu et al. in a separate paper [38]. We provide the schematic diagram of WACAL in Figure 1 and the specifications of the polarization channel in Table 1, respectively.

In WACAL, depolarization ratio measurement is performed only at $532 \mathrm{~nm}$. The polarization ratio of the laser at a wavelength of $532 \mathrm{~nm}$ is about 100:1. One telescope of the telescope assembly is utilized for the collection of elastic backscatter light in the polarization channel. One adjustable aperture is installed at the focal point of the telescope ahead of the polarization channel. The field of view (FOV) is determined by adjusting the pinhole aperture. In this study, the aperture is fixed as $2 \mathrm{~mm}$ and the FOV is determined as $1.3 \mathrm{mrad}$. The parallel and perpendicular backscattered light at a wavelength of $532 \mathrm{~nm}$ is collected to retrieve the depolarization ratio. The parallel-polarized and perpendicular-polarized light is separated by the polarizing beam splitter (PBS, CCM1-PBS-251, THORLABS) and detected by PMTs respectively. The transmissivity of the PBS for parallel-polarized signal is $95.5 \%$, while the reflectivity for perpendicular-polarized signal is larger than $99.5 \%$. The specifications of the optical elements of this channel are also listed in Table 1. To calibrate depolarization ratio measurements, one zero-order half wave plate of the type WPH10E-532 from THORLABS is installed in the receiver. To adjust its direction, the half wave plate is mounted in a manual continuous rotation mount of type CLR1 from THORLABS. Regardless of the calibration procedure, the half wave plate is always installed in the receiver. During the routine measurements, the direction of the half wave plate axis is set to be $0^{\circ}$. 


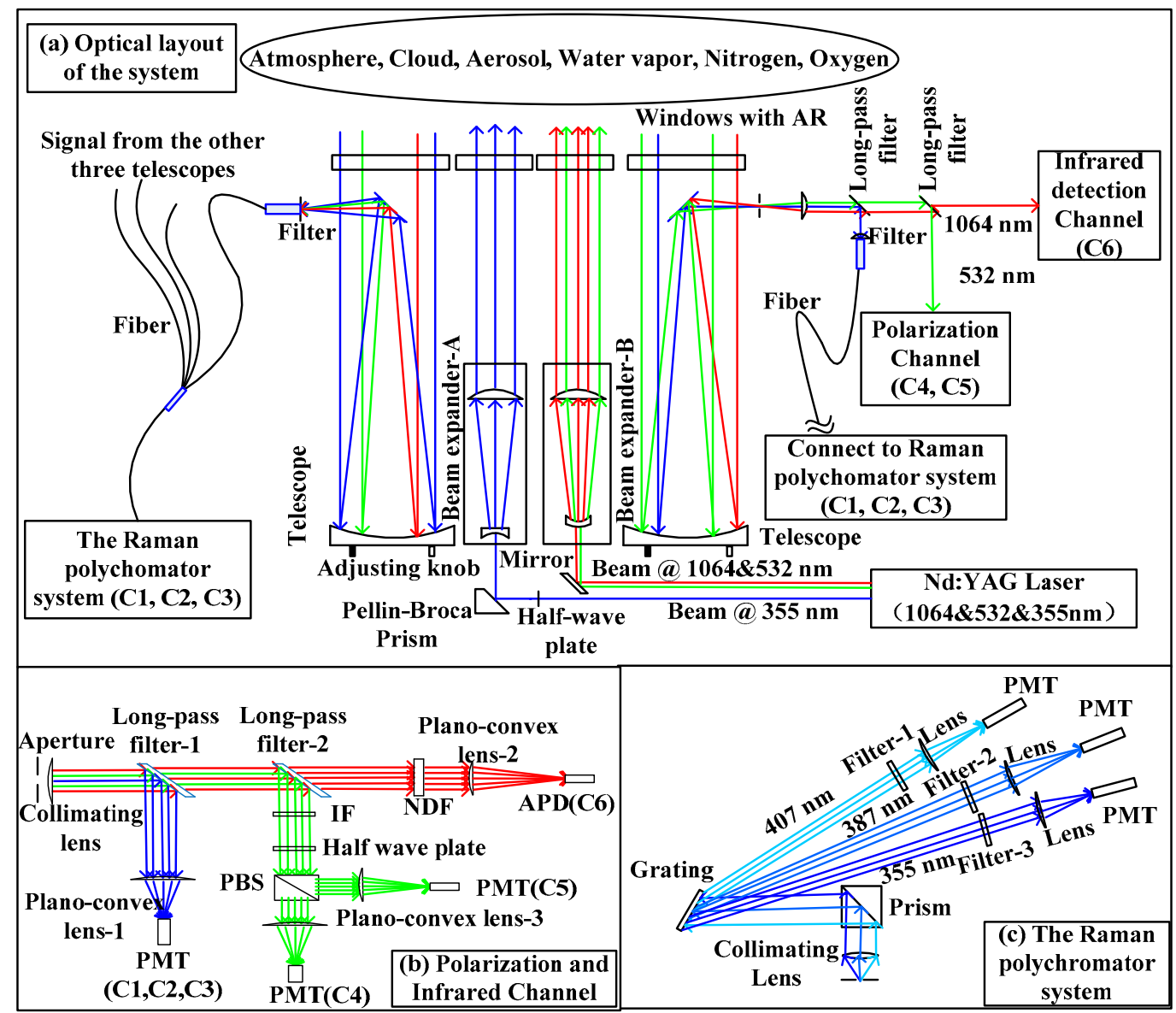

Figure 1. Optical setup of WACAL. (a) Optical layout, (b) polarization and infrared channel and (c) Raman polychromator system.

Table 1. System specification of the depolarization channel of WACAL.

\begin{tabular}{cc}
\hline Subsystem & Specification \\
\hline Laser & \\
Wavelength $(\mathrm{nm})$ & 532 \\
Pulse energy $(\mathrm{mJ})$ & 120 \\
Repetition rate $(\mathrm{Hz})$ & 30 \\
Beam divergence $(\mathrm{mrad})$ & 0.083 \\
Beam pointing stability $( \pm \mu \mathrm{rad})$ & 30 \\
Newtonian telescope & 0.308 \\
Aperture $(\mathrm{m})$ & 1.524 \\
Focal length $(\mathrm{m})$ & 1.3 \\
Field stop (mrad) & $T_{P}=95.5 \%$ \\
& $T_{S}=0.044 \%$ \\
PBS (CCM1-PBS-251) & $R_{S}>99.5 \%$ \\
& $R_{S}: R_{P} \sim 100: 1$ \\
\hline Peceiver-Photon counting acquisition & \\
PMT & Hamamatsu H10721P \\
Licel transient recorder & 3.75 \\
Range resolution (m) & 25 \\
temporal resolution (ns) & 250 \\
max count rate (MHz) &
\end{tabular}




\subsection{Methodology}

In this paper, the volume linear depolarization ratio is defined as the ratio of the cross-polarized lidar return signal $\left(P_{\perp}\right)$ to the parallel-polarized backscatter signal $\left(P_{\|}\right)[28]$.

The backscatter signals can be determined according to the lidar equation Equation (1):

$$
P=\frac{C}{r^{2}}\left(\beta_{a}+\beta_{m}\right) \exp \left\{-2 \int_{0}^{r}\left[\alpha_{m}^{\lambda}(z)+\alpha_{a}^{\lambda}(z)\right] d z\right\},
$$

where $C$ is the system constant, $\beta$ is the backscatter coefficient and $\alpha$ is the extinction coefficient. The subscripts " $m$ " and " $a$ " indicate the backscatter and extinction coefficients caused by molecules and aerosols, respectively. $P_{\|}$and $P_{\perp}$ can be described as Equations (2) and (3):

$$
P_{\|}=\frac{C_{\|}}{r^{2}}\left(\beta_{a}^{\|}+\beta_{m}^{\|}\right) \exp \left\{-2 \int_{0}^{r}\left[\alpha_{m}^{\|}(z)+\alpha_{a}^{\|}(z)\right] d z\right\},
$$

and

$$
P_{\perp}=\frac{C_{\perp}}{r^{2}}\left(\beta_{a}^{\perp}+\beta_{m}^{\perp}\right) \exp \left\{-2 \int_{0}^{r}\left[\alpha_{m}^{\perp}(z)+\alpha_{a}^{\perp}(z)\right] d z\right\} .
$$

In the polarization lidar these two polarization components are separated using the polarizing beamsplitter cubes (PBS). However, the PBS is not accurate enough to discriminate $P_{\|}$and $P_{\perp}$. As a result, the cross-talk can decrease the accuracy of the measurement inevitably.

Here the volume linear depolarization ratio $\delta^{v}[28]$ is calculated with

$$
\delta^{v}=\frac{\beta_{\perp}}{\beta_{\|}}=\frac{P_{\perp}}{P_{\|}}=\frac{P_{S} \cos ^{2} \phi+P_{P} \sin ^{2} \phi}{P_{P} \cos ^{2} \phi+P_{S} \sin ^{2} \phi} .
$$

$P_{P}$ and $P_{S}$ represent the power of parallel- and cross-polarized light after the half-wave plate respectively. $\phi$ is the transmitter-receiver misalignment angle (also called the rotation angle of the plane of polarization).

\subsection{Calibration and Cross-Check of Depolarization Ratio}

In Figure 2, the schematic diagrams for aligned and misaligned receivers are provided. Figure 2a presents a well aligned system which equips an ideal linearly polarized laser. Under this condition, the polarization plane of the laser is exactly parallel to the parallel axis of the PBS and the measured ratios of spherical particles should be zero. However, as shown in Figure 2b, misalignments between the optical axis of PBS and the transmitted beam are inevitable in general lidar systems. It leads to an erroneous calculation of the depolarization ratio [34]. In this case, a half-wave plate can be used to realign the laser polarization vector with the parallel axis of the PBS. Following Figure 2c, by using a half-wave plate, the corresponding electric field vectors for the parallel and perpendicular components incident on the PBS are given by Equations (5) and (6) [34]:

$$
\overrightarrow{E_{t, \|}}=\overrightarrow{E_{i, \|}} \cos (2 \theta)+\overrightarrow{E_{i, \perp}} \sin (2 \theta),
$$

and

$$
\overrightarrow{E_{t, \perp}}=\overrightarrow{E_{i, \perp}} \cos (2 \theta)-\overrightarrow{E_{i, \|}} \sin (2 \theta) .
$$

where $\vec{E}_{t}$ represents the field transmitted through the half-wave plate, $\vec{E}_{i}$ represents the incident field, $\theta$ is the offset angle.

The powers associated with the transmitted fields are

$$
P_{P}=E_{i, \|}^{2} \cos ^{2}(2 \theta)+E_{i, \perp}^{2} \sin ^{2}(2 \theta)
$$


and

$$
P_{S}=E_{i, \|}^{2} \sin ^{2}(2 \theta)+E_{i, \perp}^{2} \cos ^{2}(2 \theta)
$$

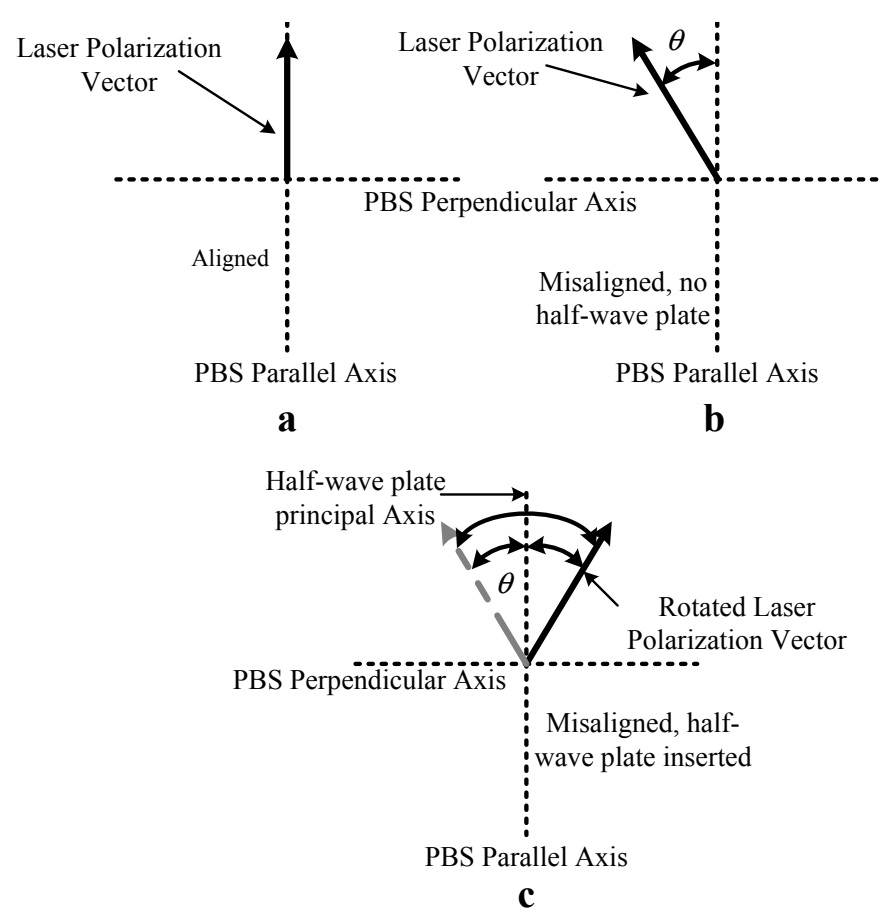

Figure 2. Receiver geometries: (a) a well aligned configuration; (b) the position of the laser polarization vector with an offset angle of $\theta$ in a receiver without half-wave plate; and (c) the position of the laser polarization vector with an offset angle of $\theta$ in a receiver with a half-wave plate. (Reproduction from [34]).

After the half-wave plate, as shown in Figure 3, the polarization directions of the backscattered light have been rotated and the power of mutually perpendicular light can be rewritten as

$$
P_{P}=\left(C_{P} / r^{2}\right) E_{0} T^{2}\left[\beta_{\|} \cos ^{2}(2 \gamma-\phi)+\beta_{\perp} \sin ^{2}(2 \gamma-\phi)\right],
$$

and

$$
P_{S}=\left(C_{S} / r^{2}\right) E_{0} T^{2}\left[\beta_{\|} \sin ^{2}(2 \gamma-\phi)+\beta_{\perp} \cos ^{2}(2 \gamma-\phi)\right] .
$$

$\gamma$ and $\phi$ denote the rotation angle of the HWP and the rotation of the plane of polarization respectively. Please note that angles on the right hand of PBS axis are positive and angles on the left size are negative.

In the WACAL system, the PBS with type of CCM1-PBS-251 is from THORLABS and the cross talk cannot be ignored. The cross talk between the transmitted and reflected light needs to be taken into consideration. As a result, the power of transmitted and reflected light through the PBS detected by the PMTs and recorded by the data acquisition can be calculated by Equations (11) and (12):

$$
P_{T}=\left(P_{P} T_{P}+P_{S} T_{S}\right) V_{T},
$$

and

$$
P_{R}=\left(P_{P} R_{P}+P_{S} R_{S}\right) V_{R}
$$




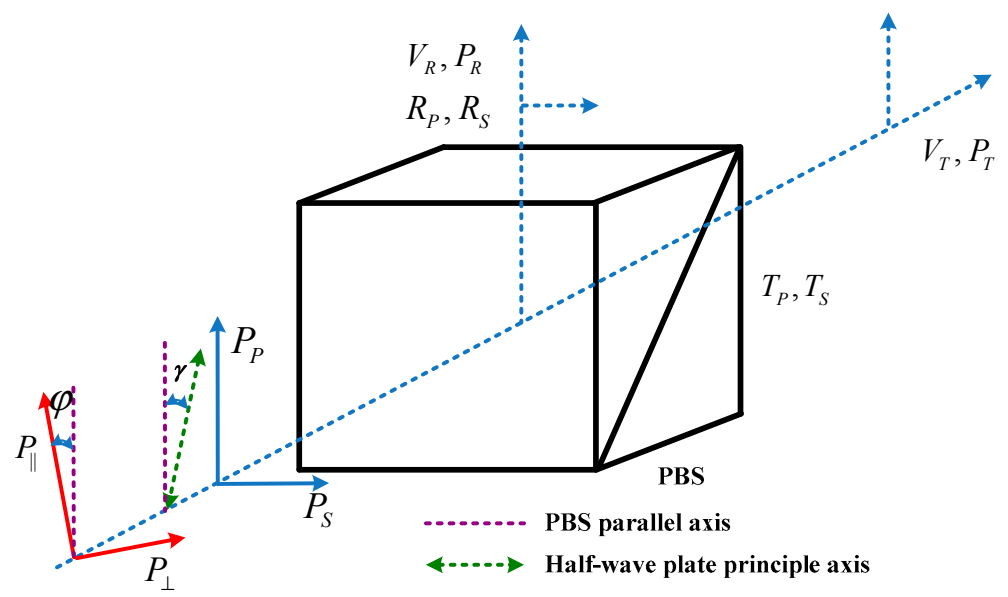

Figure 3. Signal power components in a receiver of WACAL with a PBS with the reflectivities of $R_{P}$ and $R_{S}$ and the transmittances of $T_{P}$ and $T_{S}$ for linear polarized light parallel and perpendicular to the plane of the PBS. $P_{\|}, P_{\perp}, P_{P}$ and $P_{S}$ represent the power of backscatter light at the corresponding polarization direction. (Developed from [28]).

The amplification factors $V_{T}$ and $V_{R}$ comprise the optical transmittance of the receiver and the electronic amplification in each channel. The exact values of the amplification are not necessary in this work. Furthermore, the measured ratio $m(r)$ at height of $r$ is defined as the ratio of $P_{R}$ and $P_{T}$. It can be determined by Equation (13), which is derived by taking Equations (9) and (10) into Equations (11) and (12):

$$
m(r)=G \frac{R_{S}\left[\tan ^{2}(2 \gamma-\phi)+\delta^{v}(r)\right]+R_{P}\left[1+\delta^{v}(r) \tan ^{2}(2 \gamma-\phi)\right]}{T_{P}\left[1+\delta^{v}(r) \tan ^{2}(2 \gamma-\phi)\right]+T_{S}\left[\tan ^{2}(2 \gamma-\phi)+\delta^{v}(r)\right]}
$$

where $G=V_{R} / V_{T}$ is the electro-optical gain ratio between the two channels. According to the Equations (11) and (12), the rotation angle of the plane of polarization $\phi$ can be derived corresponding to the minimum power of the perpendicular channel $P_{R}$ and the maximum power of the parallel channel $P_{T}$.

The first derivative of equations of perpendicular and parallel channels can be calculated by the equations below:

$$
\frac{d P_{R}}{d \gamma}=2 V_{R} \sin (4 \gamma-2 \phi) K\left(C / r^{2}\right) E_{0} T^{2}\left(\beta_{\|}-\beta_{\perp}\right)\left(R_{S}-R_{P}\right),
$$

and

$$
\frac{d P_{T}}{d \gamma}=2 V_{T} \sin (4 \gamma-2 \phi) K\left(C / r^{2}\right) E_{0} T^{2}\left(\beta_{\|}-\beta_{\perp}\right)\left(T_{S}-T_{P}\right) .
$$

Since $\beta_{\|}>\beta_{\perp}, R_{S}>R_{P}, T_{P}>T_{S}$, when $2 \gamma-\phi \subseteq[0,90], d P_{R} / d \gamma$ is bigger than 0 and $d P_{T} / d \gamma$ is smaller than 0 .

Consequently, as long as $2 \gamma-\phi \subseteq[0,90]$, the power of the parallel channel $P_{T}$ is a monotonically decreasing function while the power of the perpendicular channel $P_{R}$ is a monotonically increasing function.

As a conclusion, the $P_{T}$ reaches to the maximum and $P_{R}$ to the minimum conversely in the case of $2 \gamma-\phi=0^{\circ}$. When $2 \gamma-\phi=90^{\circ}$, the $P_{R}$ achieves the maximum and $P_{T}$ is the minimum. In WACAL system, by rotating the half wave plate, we can derive the angle $2 \gamma-\phi$ corresponding to the minimum power of the perpendicular channel $P_{R}$ and the maximum power of the parallel channel $P_{T}$. And the angle $\phi=2 \gamma$ is the rotation of the plane of polarization. 
The retrieval of the gain ratio $G$ is introduced in the following steps. During the process of calibration, two calibration angles of $0^{\circ}$ and $45^{\circ}$ are chosen to retrieve the gain ratio. The measured ratios can be calculated by Equations (16) and (17) respectively:

$$
m_{0^{\circ}}(r)=G \frac{R_{S}\left[\tan ^{2} \phi+\delta^{v}(r)\right]+R_{P}\left[1+\delta^{v}(r) \tan ^{2} \phi\right]}{T_{P}\left[1+\delta^{v}(r) \tan ^{2} \phi\right]+T_{S}\left[\tan ^{2} \phi+\delta^{v}(r)\right]}
$$

and

$$
m_{45^{\circ}}(r)=G \frac{R_{S}\left[1+\delta^{v}(r) \tan ^{2} \phi\right]+R_{P}\left[\tan ^{2} \phi+\delta^{v}(r)\right]}{T_{P}\left[\tan ^{2} \phi+\delta^{v}(r)\right]+T_{S}\left[1+\delta^{v}(r) \tan ^{2} \phi\right]} .
$$

The gain ratio $G$ is calculated by the method mentioned above. According to the Equation (18):

$$
G^{2}=m_{45^{\circ}}(r) m_{0^{\circ}}(r) \frac{\left[T_{P} \delta^{v}(r)+T_{S}+T_{P} \tan ^{2} \phi\right] T_{P}}{\left[R_{S} \delta^{v}(r)+R_{P}+R_{S} \tan ^{2} \phi\right] R_{S}}
$$

the gain ratio depends on the measured ratios, the specification of the PBS (i.e., the reflectivities and the transmittances) and the rotation angle of the plane of polarization.

Similarly, the gain ratio can also be determined by means of the measurement group with HWP angles of $\left(22.5^{\circ},-22.5^{\circ}\right)$ :

$$
G^{2}=m_{22.5^{\circ}}(r) m_{-22.5^{\circ}}(r) \frac{\left[T_{P} \tan ^{2}(45-\phi)+T_{S}+T_{P} \delta^{v}(r)\right]\left[T_{P}+T_{P} \tan ^{2}(45-\phi) \delta^{v}(r)+T_{S} \tan ^{2}(45-\phi)\right]}{\left[R_{S} \delta^{v}(r)+R_{P}+R_{S} \tan ^{2}(45-\phi)\right]\left[R_{S}+R_{S} \delta^{v}(r)+R_{P} \tan ^{2}(45-\phi)\right]} .
$$

When operating the calibration process, we have to select an atmospheric region where the atmospheric condition is clean. This clean air region must be stable and free of aerosol and cloud layers. After the calibration measurements, the gain ratio and the rotation angle of the plane of polarization can be obtained.

\section{Results and Error Analysis}

\subsection{Results of Gain Ratio, Volume Linear Depolarization Ratio and Particle Linear Depolarization Ratio}

The calibration experiments were operated in Qingdao on 21 September 2015, 8, 18 and 19 January 2016. By rotating the half-wave plate, the rotation of the plane of polarization $\phi$ can be determined as $5^{\circ}$. Since the calibration regions were free of aerosol, the $\delta^{v}(r)$ can be replaced by the volume linear depolarization ratio of air molecules $\delta_{m}^{v}(r)$ at the wavelength of $532 \mathrm{~nm}\left(\delta^{v}(r)=\delta_{m}^{v}(r)\right)$. Once $\phi$ and $\delta_{m}^{v}(r)$ were known, based on Equations (18) and (19), the gain ratio $G$ can be obtained.

The gain ratios obtained during the calibration experiments are provided in Figures 4 and 5 . The black lines in these figures indicate the gain ratio determined with measurement group of $\left(0^{\circ}\right.$, $\left.45^{\circ}\right)$ while the blue lines denote the gain ratio determined with measurement group of $\left(22.5^{\circ},-22.5^{\circ}\right)$. The mean value and standard deviation of gain ratio are provided as well in the panels. The red lines are the gain ratio differences between these two measurement groups.

From these calibration measurements, the standard deviation of the gain ratio from $\left(0^{\circ}, 45^{\circ}\right)$ group is about 0.05 while the standard deviation of gain ratio from $\left(22.5^{\circ},-22.5^{\circ}\right)$ group is about 0.13 . The slight deviation of gain ratios derived from these two measurement groups may result from the uncertainties of the rotation angles of the HWP. 

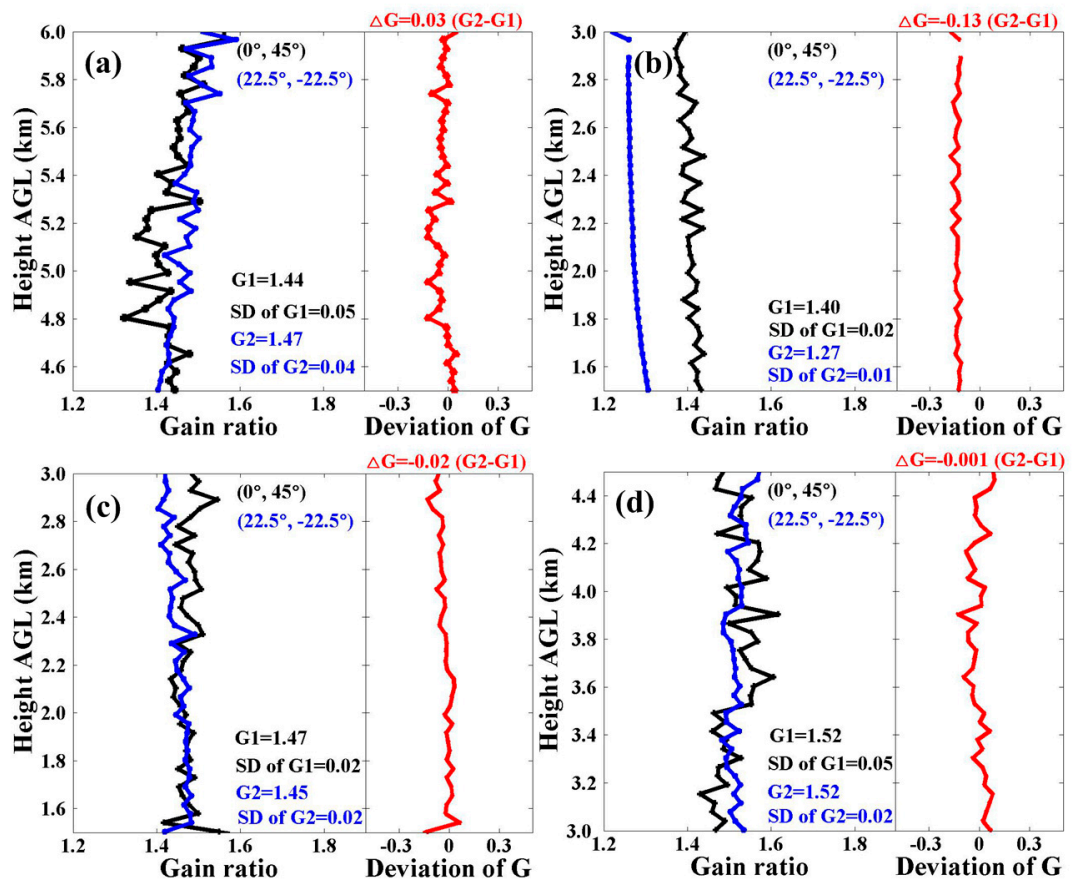

Figure 4. Gain ratio determined with different measurement groups of $\left(0^{\circ}, 45^{\circ}\right)$ and $\left(22.5^{\circ},-22.5^{\circ}\right)$ in the calibration range on (a) 21 September 2015, Qingdao; (b) 08 January 2016, Qingdao; (c) 18 January 2016, Qingdao and (d) 19 January 2016, Qingdao. The black lines indicate the gain ratio determined with measurement group of $\left(0^{\circ}, 45^{\circ}\right)$ and the blue lines denote the gain ratio determined with measurement group of $\left(22.5^{\circ},-22.5^{\circ}\right)$. The red lines are the gain ratio differences.

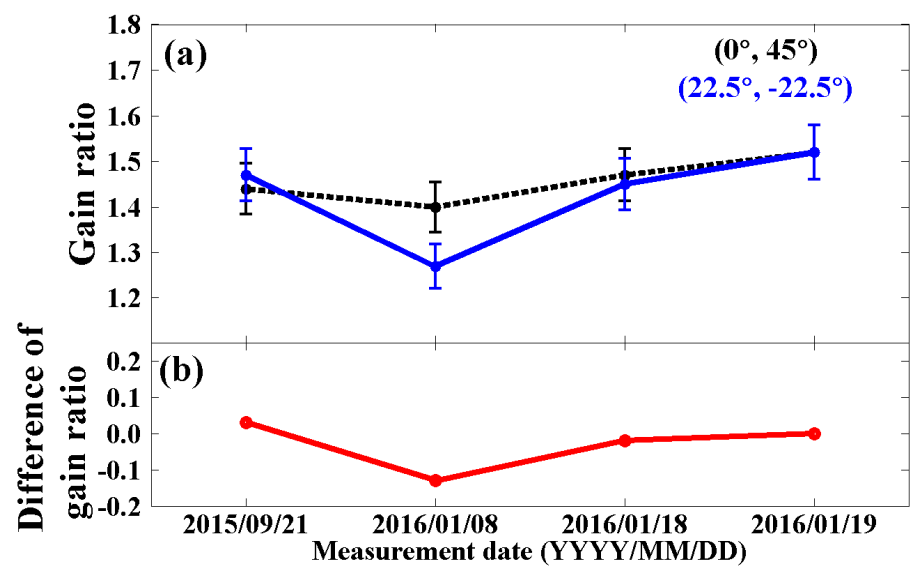

Figure 5. The (a) value and (b) deviation of gain ratios measured with different measurement groups of $\left(0^{\circ}, 45^{\circ}\right)$ and $\left(22.5^{\circ},-22.5^{\circ}\right)$ in Qingdao.

Based on Equation (4), the calibrated volume depolarization ratio can be represented as a function of component variables including the gain ratio $G$, the rotation of the plane of polarization $\phi$, the reflectivities and the transmittances of PBS via:

$$
\begin{aligned}
\delta^{v}(r) & =\frac{P_{R}(r) T_{P}-G P_{T}(r) R_{P}+\left(P_{R}(r) T_{S}-G P_{T}(r) R_{S}\right) \tan ^{2} \phi}{G P_{T}(r) R_{S}-P_{R}(r) T_{S}+\left(G P_{T}(r) R_{P}-P_{R}(r) T_{P}\right) \tan ^{2} \phi} \\
& =\frac{m(r) T_{P}-G R_{P}+\left(m(r) T_{S}-G R_{S}\right) \tan ^{2} \phi}{G R_{S}-m(r) T_{S}+\left(G R_{P}-m(r) T_{P}\right) \tan ^{2} \phi}
\end{aligned} .
$$


Once the volume depolarization ratio was calibrated, the particle linear depolarization ratio $\delta^{p}(r)$ can be retrieved via [28]

$$
\delta^{p}(r)=\frac{\left(1+\delta^{m}\right) \delta^{v}(r) R(r)-\left(1+\delta^{v}(r)\right) \delta^{m}}{\left(1+\delta^{m}\right) R(r)-\left(1+\delta^{v}(r)\right)},
$$

where $R$ is the backscatter ratio which can be retrieved by Fernald/Klett inversion [39,40].

\subsection{WACAL and CALIOP Measurements Comparison}

To cross check the performance of the calibration method, the comparison of particle depolarization ratios at wavelength of $532 \mathrm{~nm}$ from simultaneous measurements with WACAL and CALIOP were made. The CALIOP measurement data are downloaded from the Atmospheric Science Data Center, NASA (https:/ / eosweb.larc.nasa.gov/project/calipso/calipso_table). During the routine atmospheric observation in Qingdao, the simultaneous observation experiments were performed for 5 days including 30 September 2013, 19 December 2013 and 4 January 2014, 12 and 28 May 2014. Figure 6 shows the measurement tracks of CALIOP and the WACAL site. In these measurements, the range between the footprints of CALIOP and WACAL site should be less than $50 \mathrm{~km}$ (inside the black dashed circle in Figure 6).

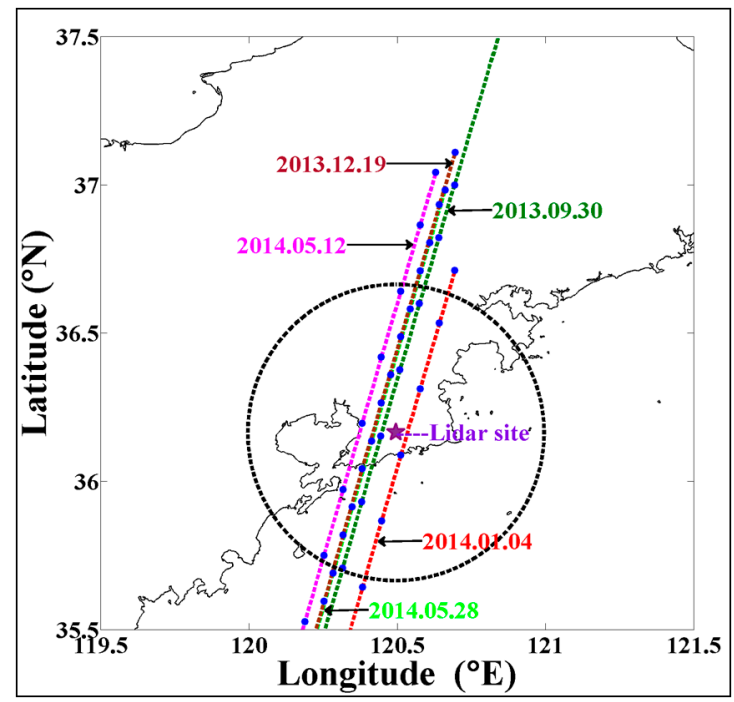

Figure 6. The track of the CALIOP and the site of the WACAL during the simultaneous measurements. The colored lines indicate the footprints of CALIOP and the purple star denotes the WACAL site. The blue solid dots indicate the footprint of CALIOP and CALIOP provides one product profile every dot. The black dashed circle represents a $50-\mathrm{km}$ radius area which is centered on WACAL. Note that the tracks of CALIOP on 19 December 2013 (purple) and 28 May 2014 (green) overlapped each other. The particle depolarization ratios are at $532 \mathrm{~nm}$ and the CALIOP measurement data are downloaded from the Atmospheric Science Data Center, NASA.

From the simultaneous observations, the particle linear depolarization ratio profiles measured with WACAL and CALIOP were obtained. For the purpose of comparison, in every measurement case, the particle depolarization ratio profile from CALIOP is averaged from the profiles (blue solid dots) inside the black dashed circle in Figure 6. Comparisons of these five cases are provided in Figure 7. From these profiles, good agreements are found. Discrepancies of the particle depolarization ratio between these two instruments mainly result from the difference between the footprint of CALIOP and the WACAL site. Considering the meteorological condition in Qingdao, the combination and interaction of atmosphere from ocean and continent make the load in the air unstable spatially and temporally. Consequently, the difference of measurement sites between WACAL and CALIOP contributes to the main deviation of particle depolarization ratio. Furthermore, because of the 
inhomogeneous atmosphere in the boundary layer, WACAL and CALIOP may measure different air mass during the simultaneous measurements, which result in the particle depolarization ratio differences in the lower heights.
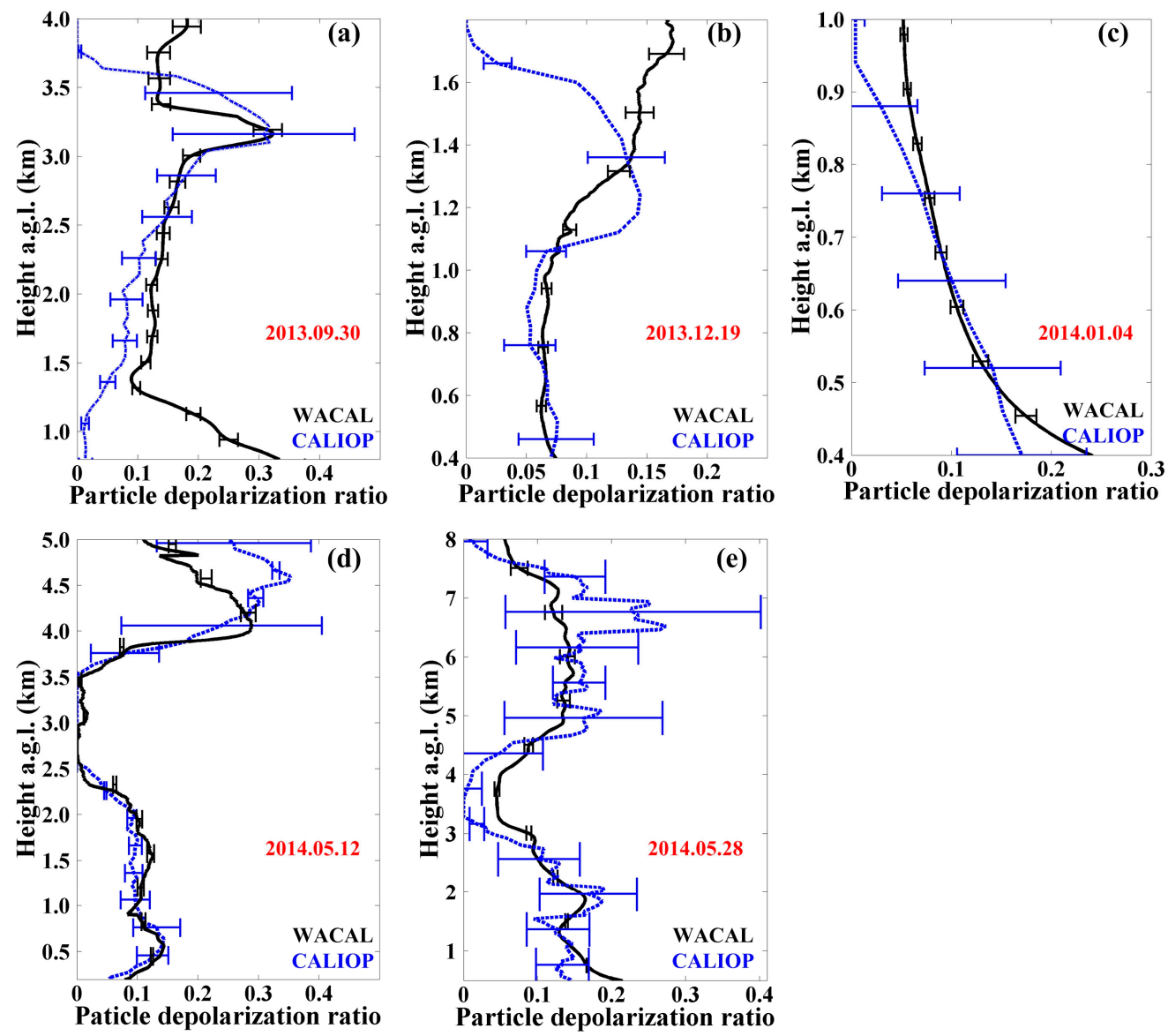

Figure 7. Comparisons of particle depolarization ratios from WACAL and CALIOP during the simultaneous observations on (a) 30 September 2013; (b) 19 December 2013; (c) 01 January 2014; (d) 12 May 2014 and (e) 28 May 2014, respectively.

\subsection{Error Analysis of Gain Ratio, Calibrated Volume and Particle Depolarization Ratio}

\subsubsection{Error of Gain Ratio}

With the calibration method proposed in this paper, the gain ratio can be determined. In order to evaluate its accuracy, the error should also be calculated. Take the measurement group of $\left(0^{\circ}, 45^{\circ}\right)$ as an example for error analysis. The total error of the gain ratio includes systematic and random errors and can be expressed by

$$
\left(\left.\frac{\Delta G}{G}\right|_{\text {total }}\right)^{2}=\left(\left.\frac{\Delta G}{G}\right|_{\text {systematic }}\right)^{2}+\left(\left.\frac{\Delta G}{G}\right|_{\text {random }}\right)^{2}=F_{m}^{G}\left[\left(\frac{\Delta m_{0^{\circ}}}{m_{0}}\right)^{2}+\left(\frac{\Delta m_{45^{\circ}}}{m_{45^{\circ}}}\right)^{2}\right]+F_{\phi}^{G}\left(\frac{\Delta \phi}{\phi}\right)^{2},
$$

where $\Delta$ is the uncertainty associated with the various quantities and the propagation factor $F_{x}^{f(x)}$ is defined as

$$
F_{x}^{f(x)}=\left(\frac{x}{f(x)} \frac{\partial f(x)}{\partial x}\right)^{2}
$$

The propagation factor is a factor by which the relative error in $f(x)$ is magnified with respect to the relative error in the component variables $x$. 
In this study, the random error is introduced by measured ratio and it is calculated via [41]

$$
\left.\frac{\Delta G}{G}\right|_{\text {random }}=\sqrt{\frac{1}{4}\left(\frac{\Delta m_{0^{\circ}}}{m_{0^{\circ}}}\right)^{2}+\frac{1}{4}\left(\frac{\Delta m_{45^{\circ}}}{m_{45^{\circ}}}\right)^{2}} .
$$

The systematic error is caused by the bias of $\phi$ and it is determined by

$$
\left.\frac{\Delta G}{G}\right|_{\text {systematic }}=\sqrt{\left\{\phi \frac{\left[\left(R_{S} \delta^{v}(r)+R_{P}+R_{S} \tan ^{2} \phi\right) R_{S}-\left(T_{P} \delta^{v}(r)+T_{S}+T_{P} \tan ^{2} \phi\right) T_{P}\right]}{\left[T_{P} \delta^{v}(r)+T_{S}+T_{P} \tan ^{2} \phi\right]\left[R_{S} \delta^{v}(r)+R_{P}+R_{S} \tan ^{2} \phi\right] R_{S} T_{P}}\right\}^{2}\left(\frac{\triangle \phi}{\phi}\right)^{2}} .
$$

Since the $F_{\phi}^{G}$ is far smaller than 1 , the error introduced by offset angle $\phi$ can be ignored. Therefore, the Equation (22) is simplified as

$$
\left.\frac{\Delta G}{G}\right|_{\text {total }}=\sqrt{\frac{1}{4}\left(\frac{\Delta m_{0^{\circ}}}{m_{0^{\circ}}}\right)^{2}+\frac{1}{4}\left(\frac{\triangle m_{45^{\circ}}}{m_{45^{\circ}}}\right)^{2}},
$$

Following Equations (22) and (23), the error of the gain ratio determined with measurement group of $\left(22.5^{\circ},-22.5^{\circ}\right)$ can also be obtained via

$$
\left.\frac{\Delta G}{G}\right|_{\text {total }}=\sqrt{\frac{1}{4}\left(\frac{\Delta m_{22.5^{\circ}}}{m_{22.5^{\circ}}}\right)^{2}+\frac{1}{4}\left(\frac{\Delta m_{-22.5^{\circ}}}{m_{-22.5^{\circ}}}\right)^{2}}
$$

The error of measured ratio is calculated by

$$
\begin{aligned}
& \left(\frac{\Delta m}{m}\right)^{2}=\left(\frac{\triangle_{P_{T}}}{P_{T}}\right)^{2}+\left(\frac{\triangle_{P_{R}}}{P_{R}}\right)^{2}=\frac{1}{S N R_{P_{T}}{ }^{2}}+\frac{1}{S N R_{P_{R}}{ }^{2}}, \\
& S N R_{P_{x}}{ }^{2}=\frac{P_{x}{ }^{2}}{P_{x}+P_{\text {background }}}
\end{aligned}
$$

where $P_{\text {background }}$ is the background of the signal.

\subsubsection{Error of Calibrated Volume Depolarization Ratio}

In this section, the error analysis of the calibrated volume depolarization ratio is provided. The total error of the volume depolarization ratio is determined with

$$
\begin{aligned}
& \left(\left.\frac{\Delta \delta^{v}}{\delta^{v}}\right|_{\text {total }}\right)^{2}=\left(\left.\frac{\Delta \delta^{v}}{\delta^{v}}\right|_{\text {systematic }}\right)^{2}+\left(\left.\frac{\Delta \delta^{v}}{\delta^{v}}\right|_{\text {random }}\right)^{2} \\
& \left(\left.\frac{\Delta \delta^{v}}{\delta^{v}}\right|_{\text {systematic }}\right)^{2}=F_{G}^{\delta^{v}}\left(\frac{\Delta G}{G}\right)^{2}+F_{\phi}^{\delta^{v}}\left(\frac{\Delta \phi}{\phi}\right)^{2} \\
& \left(\left.\frac{\Delta \delta^{v}}{\delta^{v}}\right|_{\text {random }}\right)^{2}=F_{m}^{\delta^{v}}\left(\frac{\Delta m}{m}\right)^{2}
\end{aligned}
$$

Assuming $\delta^{v}=A / B, A_{x}^{\prime}=\partial A / \partial x$ and $B \prime_{x}=\partial B / \partial x$, the propagation factor can be represented as

$$
F_{x}^{\delta^{v}}=x^{2}\left(\frac{A_{x}^{\prime 2}}{A^{2}}+\frac{B_{x}^{\prime 2}}{B^{2}}-\frac{2 A_{x}^{\prime} B_{x}^{\prime}}{A B}\right) .
$$

From (30), this factor varies with the gain ratio $G$, the rotation of the plane of polarization $\phi$ and the measured ratio $m$. To illustrate the behavior of the volume depolarization ratio typical error, Table 2 gives some examples of the volume depolarization ratio and its propagated error from mean values of the measured ratio, the gain ratio and the rotation angle of the plane of polarization. Please note that the measured ratio error depends on measurements. The value of $5 \%$ is only used for instance in this table. It is variable in routine measurements. 
From Table 2 and Figure 8, it is evident that the propagation factor of the gain ratio $F_{G}^{\delta^{v}}$ is always small and is typically between 0 and 1 . The propagation factors of the polarization plane $F_{\phi}^{\delta^{v}}$ and of the measured ratio $F_{m}^{\delta^{v}}$ vary depending on the measured ratio. It can be found that in the case of the large values of the measured ratio, the volume linear depolarization ratio is mainly effected by errors of the measured ratio and the gain ratio. And in the case of the small values of the measured ratio, the volume linear depolarization ratio is mainly effected by the errors of the measured ratio and the offset angle. Thus, the error of the offset angle $\phi$ has little influence in detection of aerosols with large depolarization ratio, e.g., dust. However, it cannot be ignored since its pronounced impact on the detection of aerosols with small depolarization ratio, e.g., marine aerosol and biomass burning. From this perspective, the calibration for the offset angle is critical. Different from the influence of the error of $\phi$, the error of the gain ratio has distinct impact on the detection of aerosols with large depolarization ratio but causes little impact on detection of aerosols with small depolarization ratio.

Table 2. Error of volume depolarization ratio propagated from the errors in the gain ratio, the measured ratio and the rotation angle of the plane of polarization. Note that the error of the measured ratio $m$, depends on measurements. The value $5 \%$ is only used for instance in this table. It is variable in routine measurements.

\begin{tabular}{ccccccc}
\hline $\mathbf{m}$ & $\mathbf{G}$ & $\boldsymbol{\phi}$ & $\boldsymbol{F}_{\boldsymbol{G}}^{\delta^{v}}$ & $\boldsymbol{F}_{\boldsymbol{\phi}}^{\delta^{v}}$ & $\boldsymbol{F}_{m}^{\delta^{v}}$ & $\boldsymbol{\delta}^{v}$ \\
\hline $0.1 \pm 5 \%$ & $1.465 \pm 3.3 \%$ & $5 \pm 5 \%$ & 0.34 & 6.19 & 6.69 & $0.03 \pm 28 \%$ \\
$0.3 \pm 5 \%$ & $1.465 \pm 3.3 \%$ & $5 \pm 5 \%$ & 0.55 & 0.14 & 1.59 & $0.16 \pm 7.8 \%$ \\
$0.6 \pm 5 \%$ & $1.465 \pm 3.3 \%$ & $5 \pm 5 \%$ & 0.79 & 0.023 & 1.27 & $0.36 \pm 6.5 \%$ \\
$0.7 \pm 5 \%$ & $1.465 \pm 3.3 \%$ & $5 \pm 5 \%$ & 0.82 & 0.015 & 1.23 & $0.42 \pm 6.4 \%$ \\
\hline
\end{tabular}

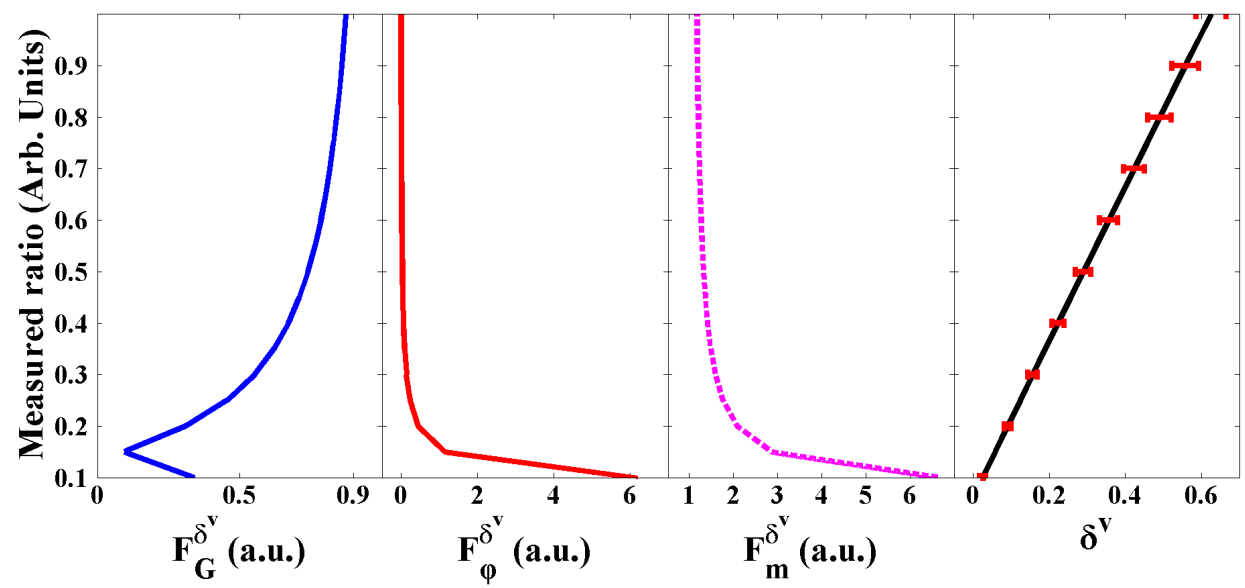

Figure 8. (a) Propagation factor of the gain ratio $F_{G}^{\delta^{v}}$; (b) propagation factor of the offset angle $F_{\phi}^{\delta^{v}}$; (c) propagation factor of the measured ratio $F_{m}^{\delta^{v}}$ and (d) correlation between volume depolarization ratio and the measured ratio.

\subsubsection{Error of Particle Depolarization Ratio}

Once the volume depolarization ratio was calibrated, the particle depolarization ratio can be determined via Equation (21). The error of the particle depolarization ratio can be calculated by

$$
\left(\frac{\triangle \delta^{p}(r)}{\delta^{p}(r)}\right)^{2}=F_{R}^{\delta^{p}}\left(\frac{\triangle R(r)}{R(r)}\right)^{2}+F_{\delta^{v}}^{\delta^{p}}\left(\frac{\triangle \delta^{v}(r)}{\delta^{v}(r)}\right)^{2} .
$$

The propagation factors $F_{R}^{\delta^{p}}$ and $F_{\delta^{v}}^{\delta^{p}}$ are determined by Equation (23). 


\section{Observations and Discussion}

\subsection{Observation Campaigns-TIPEX III 2013 and TIPEX III 2014}

The calibration method was applied in TIPEX III in 2013 and 2014 in China. The two depolarization observation field experiments were performed in the Tibetan Plateau in Litang $\left(30.03^{\circ} \mathrm{N}, 100.28^{\circ} \mathrm{E}\right.$, $3949 \mathrm{~m}$ above sea level (a.s.l.)) in 2013 and in Naqu (31.48 $\mathrm{N}, 92.06^{\circ} \mathrm{E}, 4508 \mathrm{~m}$ a.s.l.) in 2014. Figure 9 shows the locations and Table 3 presents the measurement time of these two campaigns.

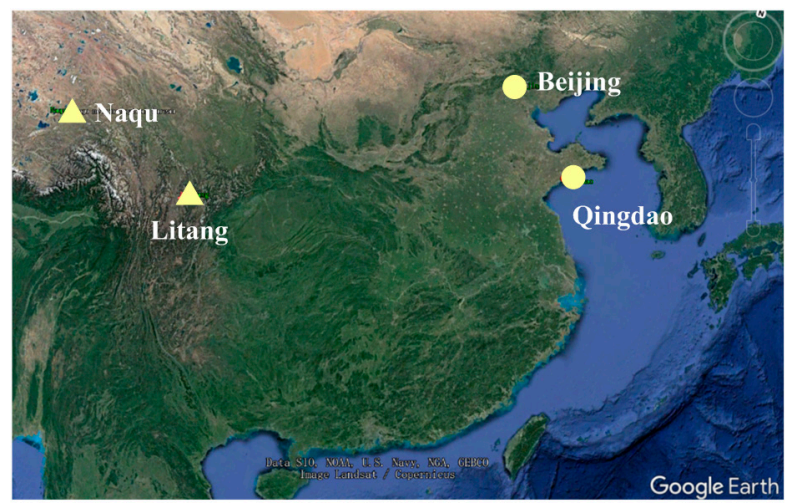

Figure 9. Locations of TIPEX III sites in Litang and Naqu. Map: Google Earth (January 2018).

Table 3. Summary of the measurement of the water vapor, cloud and aerosol lidar.

\begin{tabular}{cccc}
\hline Site & Location & Mission & Measurement Time \\
\hline Litang, Sichuan province & $\left(30.03^{\circ} \mathrm{N}, 100.28^{\circ} \mathrm{E}, 3949 \mathrm{~m}\right.$ a.s.l $)$ & TIPEX III 2013 & 14 July 2013 to 2 August 2013 \\
\hline $\begin{array}{c}\text { Naqu, The Tibet } \\
\text { Autonomous Region }\end{array}$ & $\left(31.48^{\circ} \mathrm{N}, 92.06^{\circ} \mathrm{E}, 4508 \mathrm{~m}\right.$ a.s.l. $)$ & TIPEX III 2014 & 6 July 2014 to 31 August 2014 \\
\hline
\end{tabular}

\subsection{Aerosol and Mid-Level Clouds Observations and Discussions}

Two case studies during the campaigns listed in Table 3 were selected for analysis related to the measurements of the polarization state of the mid-level cloud systems and boundary layer aerosol.

During the TIPEX III 2013 in Litang, the depolarization ratio calibration process was performed at the night of 30 July 2013. It was rainy in that afternoon and the atmosphere was very clean after the rainfall. In Figure 10a, the gain ratio is presented. Then it is applied in the depolarization ratio measurements. The observations on 28 July during the TIPEX III 2013 in Litang are chosen as a measurement case. From the profile and temporal development of particle depolarization ratio shown in Figure 10, the particle depolarization ratio of the clouds located at a height of $3.7-4.5 \mathrm{~km}$ above ground level (a.g.l.) is $0.19 \pm 0.03$. The clouds can be classified as mixed phase clouds. From all the measurements in this campaign, most mid-level clouds over Litang have similar characteristics in summertime and the clouds in Figure 10c are proposed to be typical cases. Another layer was suspended between $2.5 \mathrm{~km}$ and $3.6 \mathrm{~km}$ a.g.l. below the clouds. The particle depolarization ratio of this layer is $0.08 \pm 0.001$. The backscatter coefficient of this layer is $0.031(\mathrm{~km} \mathrm{sr})^{-1} \pm 0.005(\mathrm{~km} \mathrm{sr})^{-1}$, which is much smaller than the backscatter coefficient of the clouds. Consequently, this layer is an aerosol layer. From Figure 10c, a thin clean atmosphere region between the clouds and the aerosol layer can be found. Furthermore, the particle depolarization ratio near the ground is $0.04 \pm 0.01$. Consequently, the aerosol load in Litang near the ground is rare and free of non-spherical particles such as biomass burning aerosols $\left(0.1<\delta^{p}<0.2\right)$ and pure dust $\left(0.2<\delta^{p}<0.4\right)$ [23]. 

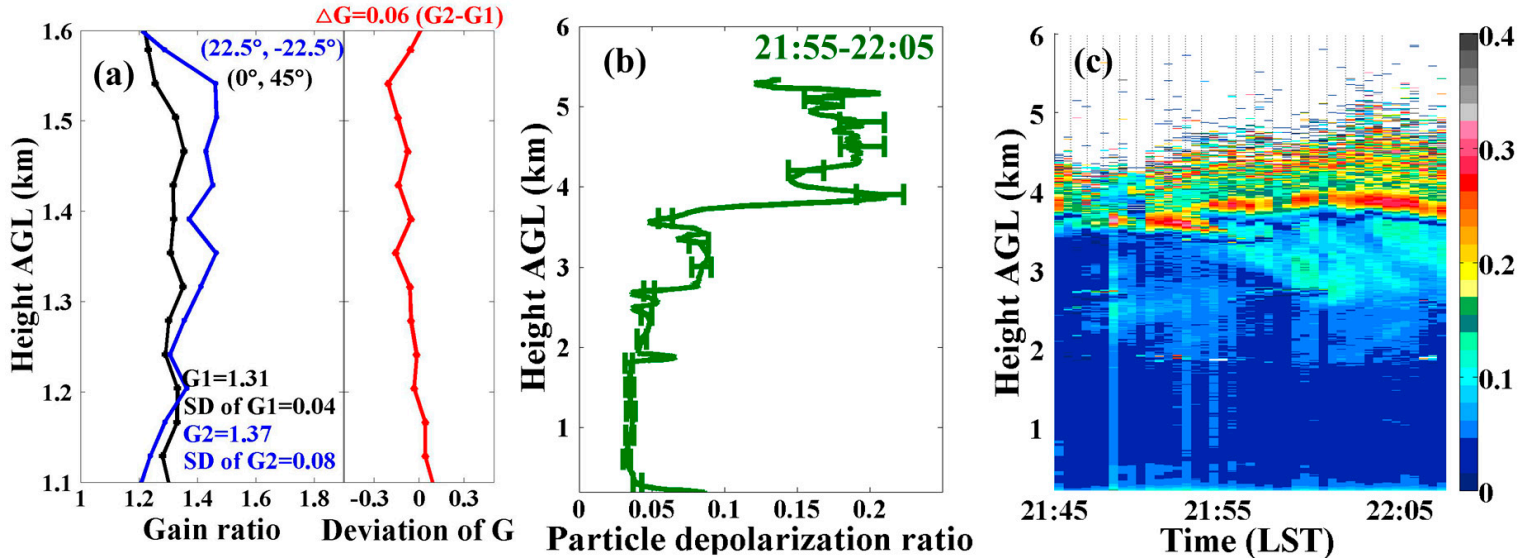

Figure 10. (a) Gain ratio determined during TIPEX III 2013 in Litang; (b) Profile of particle depolarization ratio (dark green line) with error bar (horizontal line) and (c) temporal development of particle depolarization ratio measured on 28 July 2013 in Litang.

During the TIPEX III 2014 in Naqu, the depolarization ratio calibration process was operated at the night of 26 July 2014. On that day, the atmospheric condition was clean and cloudless. In Figure 11a, the gain ratio is provided and then it is applied to the volume linear depolarization ratio and particle linear depolarization ratio measurements. The observation on 12 August is chosen as a case study. In Figure 11b,c, temporal changes of the particle depolarization ratio of the clouds and ground aerosols are shown. Classified by the volume depolarization ratio $(0.084 \pm 0.01)$, the clouds locating at the range of $2.5-3.3 \mathrm{~km}$ a.g.l. are water clouds. The particle depolarization ratio of the atmosphere near ground is $0.16 \pm 0.02$, which indicates the load of nonspherical aerosols. Since the solar background light was strong at this moment in Naqu, the ground heating was still ongoing. We propose that the nonspherical aerosols may be the mixture of anthropogenic aerosol (such as biomass burning aerosols) and local dust. In Figure 11b, the particle depolarization ratios measured at 19:30-19:40 and 19:40-19:50 are presented. We can find that the particle depolarization ratios inside clouds are stable while the particle depolarization ratios near the ground are slight larger over time. Please note that the white areas in Figure 11c indicate too low signal-to-noise ratios (SNR) caused by the strong sun light. So that a good retrieval of depolarization ratio was not possible.
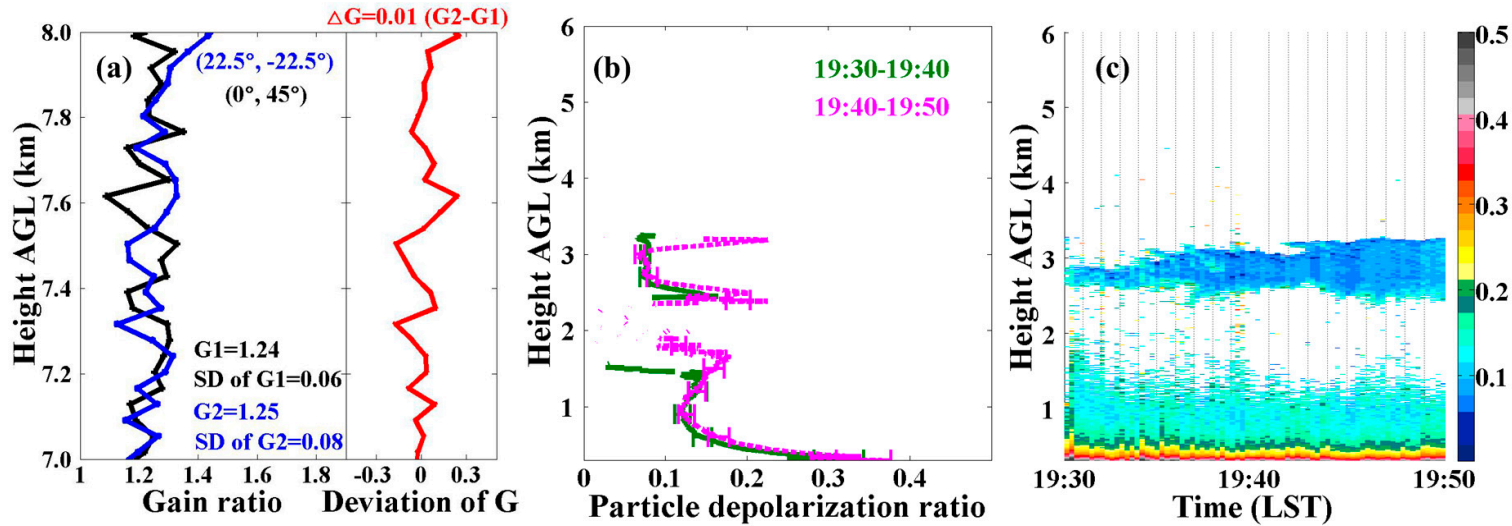

Figure 11. (a) Gain ratio determined during TIPEX III 2014 in Naqu; (b) Profile of particle depolarization ratio (dark green line) with error bar (horizontal line) and (c) temporal development of particle depolarization ratio measured on 12 August 2014 in Naqu. 


\subsection{High-Level Clouds Observations and Discussions}

In July and August, the high-altitude cirrus occurrence probability is in Naqu high. High altitude cirrus clouds have been identified as one important regulator of the radiance balance of the earth-atmosphere system [42]. During the TIPEX III, several cirrus conditions were observed and all of the measurements are presented in Figure 12. Based on their heights, they are divided into 21 separate cirrus systems. For further analysis, the cirrus clouds particle depolarization ratio and base/top heights are derived. In this study, the cirrus cloud base heights and top heights are determined with an algorithm that combined "differential zero-cross algorithm" and "threshold algorithm" [38]. The particle depolarization ratios and heights of cirrus are summarized in Table 4 . In Table 4, the mean values and standard deviations of particle depolarization ratios and heights are provided.

In Figure 13a-c, the cirrus structures, the occurrence frequency of cirrus cloud base/top heights and cirrus middle height are presented. Note that in Figure 13a, the x-axis label corresponds to the cirrus serial number in Table 4 . The results show that cirrus clouds are occurring between $5.2 \mathrm{~km}$ and $12 \mathrm{~km}$ a.g.l. The cloud thickness ranges from 0.12 to $2.55 \mathrm{~km}$ with a mean thickness of $1.22 \pm 0.70 \mathrm{~km}$. The particle depolarization ratio differs from 0.36 to 0.52 , with a mean value of $0.44 \pm 0.04$. Then the height dependence of particle depolarization ratio is investigated. In Figure 13d, the correlation between cirrus middle height and particle depolarization ratio is provided. The vertical bars present the statistical uncertainties of cirrus particle depolarization ratio and the black line is the fitted curve. Similar with the results of mid-latitude cirrus clouds from Sassen and Benson, 2001 [9] and Chen et al., 2002 [10], It is found the particle depolarization ratios of cirrus clouds become larger with the height increase. Furthermore, a two-order polynomial function is found between heights and particle depolarization ratios of cirrus clouds over the Tibetan Plateau, which means that the increase rate of particle depolarization ratio decrease as the height increase. With the increase of cirrus middle height, the temperature gradually decreases. At these lower temperatures, the irregular types of ices with larger size and greater distortion are formed, which result in the increase of particle depolarization ratio of the cirrus clouds. Additionally, the height dependence of cirrus particle depolarization ratio at lower height is stronger than that at higher heights. This should be explained by the evolution of the cirrus particles at different heights and temperatures. Under the condition of extremely high height and low temperature, the cirrus particles become large and stable, which weaken their height dependence and temperature dependence.

Table 4. Heights and depolarization ratio of cirrus measured in Naqu.

\begin{tabular}{|c|c|c|c|c|c|}
\hline $\begin{array}{l}\text { Cirrus Serial } \\
\text { Number }\end{array}$ & $\begin{array}{l}\text { Measurement } \\
\text { Date }\end{array}$ & $\begin{array}{c}\text { Cirrus Base Height } \\
\text { (a.g.1., km) }\end{array}$ & $\begin{array}{l}\text { Cirrus Top Height } \\
\text { (a.g.1., km) }\end{array}$ & $\begin{array}{l}\text { Mean Values } \\
\text { of } \delta^{p}\end{array}$ & $\begin{array}{c}\text { Standard } \\
\text { Deviation of } \delta^{p}\end{array}$ \\
\hline 1 & 10 July 2014 & $7.10 \pm 0.75$ & $8.15 \pm 0.77$ & 0.45 & 0.03 \\
\hline 2 & 10 July 2014 & $11.51 \pm 0.82$ & $12.02 \pm 0.52$ & 0.48 & 0.02 \\
\hline 3 & 11 July 2014 & $7.16 \pm 0.72$ & $8.45 \pm 0.78$ & 0.47 & 0.02 \\
\hline 4 & 18 July 2014 & $5.21 \pm 0.30$ & $5.66 \pm 0.30$ & 0.36 & 0.04 \\
\hline 5 & 18 July 2014 & $7.89 \pm 0.44$ & $8.78 \pm 0.64$ & 0.47 & 0.02 \\
\hline 6 & 18 July 2014 & $11.48 \pm 0.13$ & $11.80 \pm 0.12$ & 0.47 & 0.02 \\
\hline 7 & 19 July 2014 & $5.55 \pm 0.40$ & $6.09 \pm 0.44$ & 0.35 & 0.03 \\
\hline 8 & 21 July 2014 & $8.03 \pm 1.28$ & $9.66 \pm 0.40$ & 0.52 & 0.06 \\
\hline 9 & 22 July 2014 & $6.27 \pm 0.36$ & $7.02 \pm 0.42$ & 0.40 & 0.04 \\
\hline 10 & 22 July 2014 & $9.08 \pm 0.22$ & $10.38 \pm 0.62$ & 0.44 & 0.03 \\
\hline 11 & 27 July 2014 & $6.19 \pm 0.58$ & $7.16 \pm 0.94$ & 0.44 & 0.02 \\
\hline 12 & 27 July 2014 & $7.61 \pm 0.61$ & $8.14 \pm 0.52$ & 0.47 & 0.02 \\
\hline 13 & 31 July 2014 & $5.62 \pm 0.33$ & $6.34 \pm 0.26$ & 0.41 & 0.08 \\
\hline 14 & 31 July 2014 & $8.05 \pm 0.37$ & $8.94 \pm 0.35$ & 0.42 & 0.07 \\
\hline 15 & 4 August 2014 & $6.02 \pm 0.60$ & $8.56 \pm 0.69$ & 0.39 & 0.03 \\
\hline 16 & 4 August 2014 & $9.72 \pm 0.39$ & $11.17 \pm 0.76$ & 0.39 & 0.02 \\
\hline 17 & 6 August 2014 & $6.19 \pm 0.38$ & $6.32 \pm 0.33$ & 0.42 & 0.02 \\
\hline 18 & 6 August 2014 & $7.52 \pm 0.32$ & $8.77 \pm 0.28$ & 0.45 & 0.02 \\
\hline 19 & 6 August 2014 & $8.10 \pm 0.28$ & $9.18 \pm 1.13$ & 0.45 & 0.01 \\
\hline 20 & 8 August 2014 & $6.12 \pm 0.45$ & $6.77 \pm 0.53$ & 0.44 & 0.03 \\
\hline 21 & 8 August 2014 & $6.45 \pm 0.44$ & $7.45 \pm 0.54$ & 0.41 & 0.03 \\
\hline
\end{tabular}



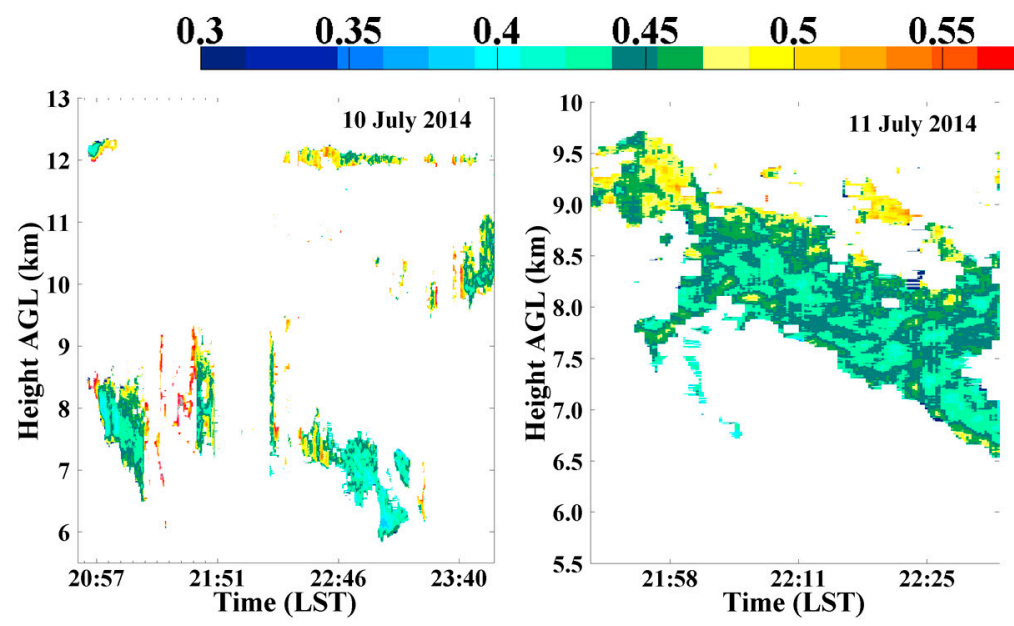

$0.6 \quad 0.65$

0.7
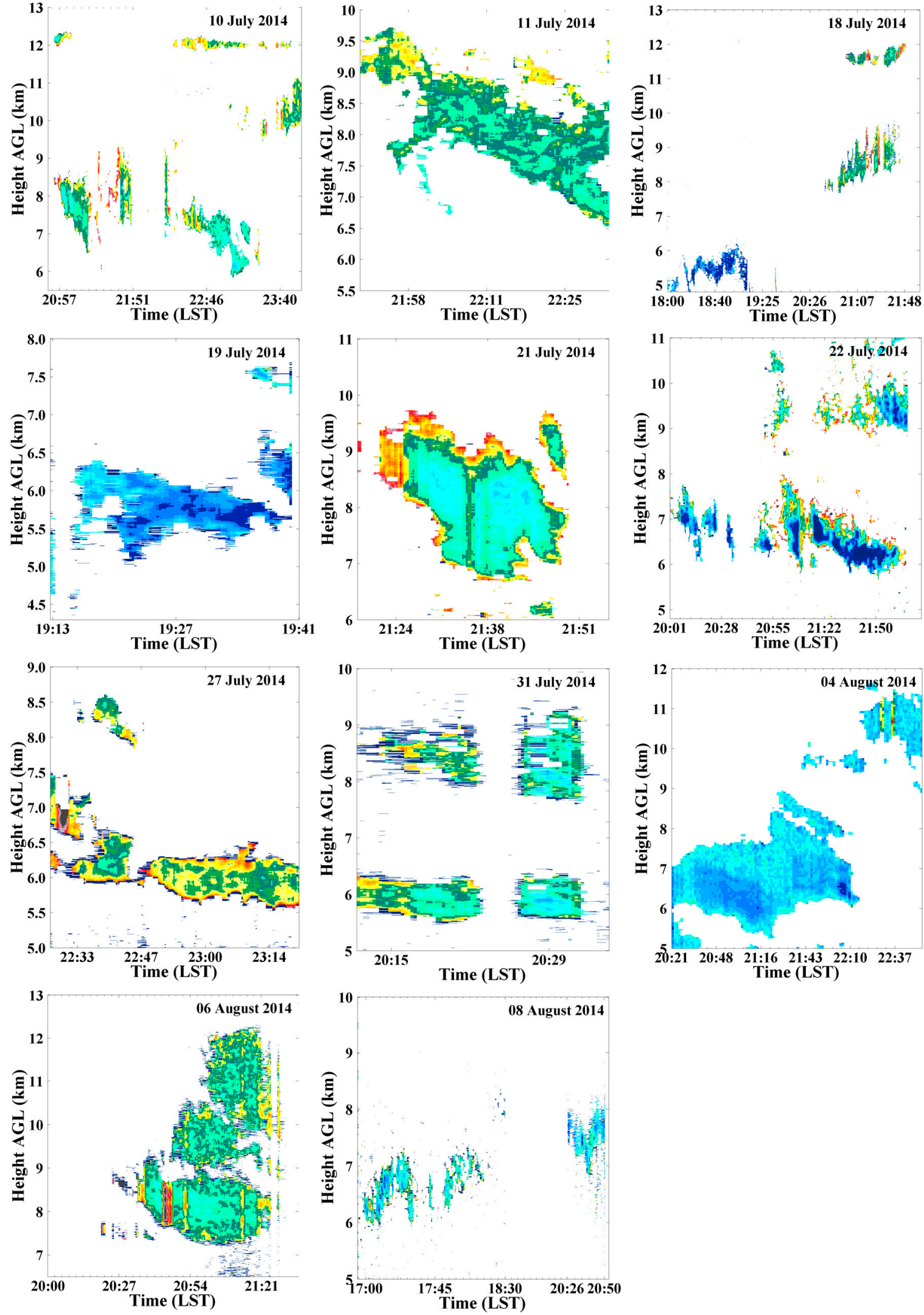

Figure 12. Particle depolarization ratio of cirrus measured during TIPEX III in Naqu. 

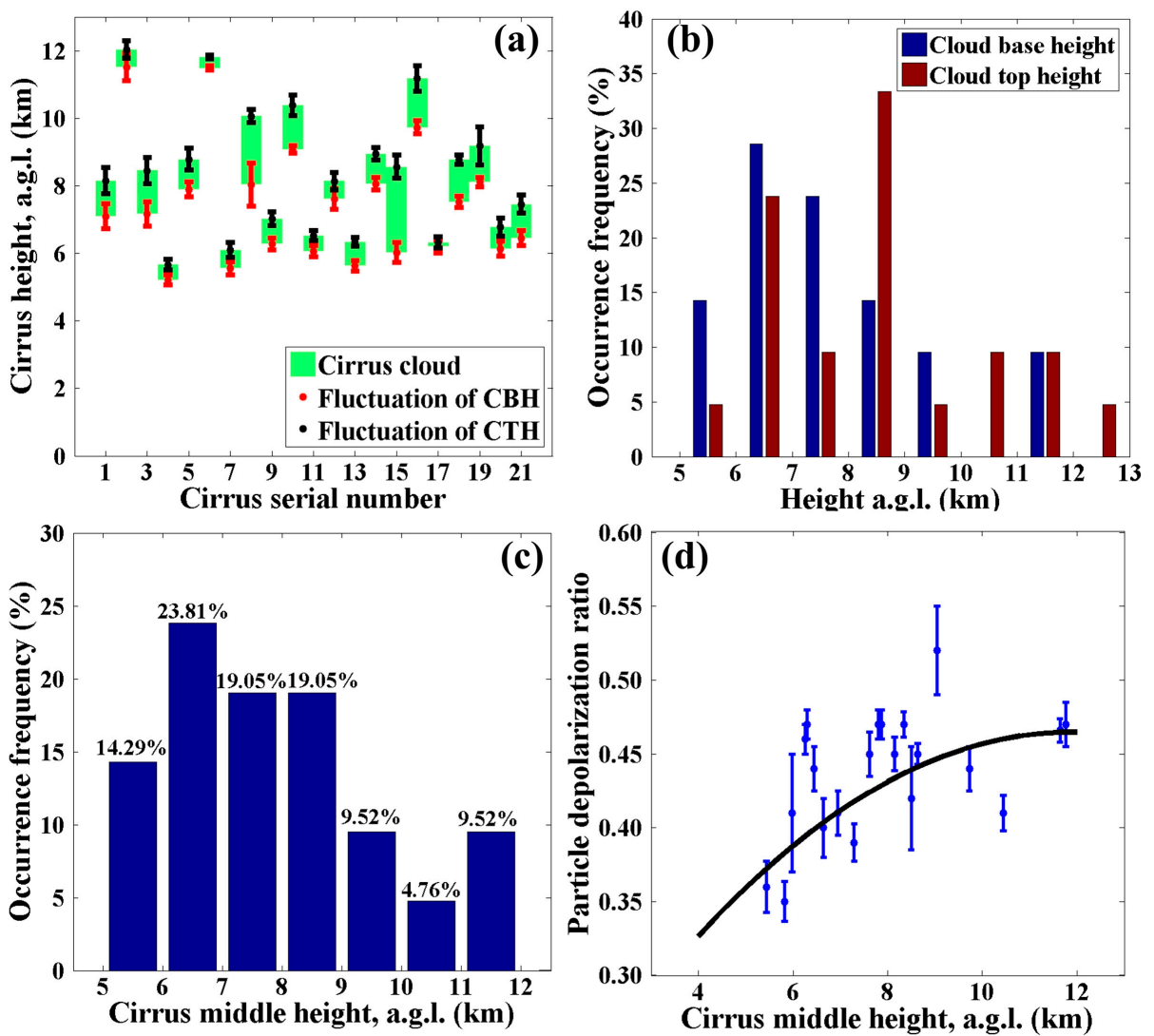

Figure 13. Measurements of cirrus clouds during TIPEX III 2014 in Naqu. (a) Cirrus structure and (b) the frequency occurrence of cloud base/top heights; (c) Frequency occurrence of cirrus cloud middle height and (d) correlation between particle depolarization ratio and cirrus middle height.

\section{Conclusions}

In this study, an application of the " $\Delta 90^{\circ}$-calibration" method modified to fit the particular system of WACAL is presented, as well as the error analysis. We also presented atmospheric observations during TIPEX III 2013 and TIPEX III 2014. Using WACAL, we observed the atmosphere over the Tibetan Plateau and obtained information of the aerosol and cloud polarizing properties. The key findings of this study are summarized as below:

(1) The calibration method for volume linear depolarization ratio is presented and the error analysis is provided. In this method, the influences of the gain ratio, the rotation of the plane of polarization and the cross talk of polarizing beam splitter are determined by using a half wave plate. Two groups of calibration measurements are operated and the results are compared. The calibrated particle depolarization ratio is also compared with the particle depolarization ratio from simultaneous measurements with CALIOP and good agreements are found.

(2) Based on the error analysis, the gain ratio determined in this paper is mainly effected by the random error of measured ratios at $\left(0^{\circ}, 45^{\circ}\right)$ and $\left(22.5^{\circ},-22.5^{\circ}\right)$. The offset angle $\phi$ has a small effect on the determination of gain ratio. However, the polarized backscatter light must be strictly rotated by $90^{\circ}$ (equivalent to half wave plate strictly rotated by $45^{\circ}$ ) in this method. The errors of the volume depolarization ratio are introduced by the errors of the measured ratio, the offset angle and the gain ratio. The influences of them vary depending on the polarization properties of the measured air mass.

(3) The calibration method is applied in TIPEX 2013 and TIPEX 2014. By mean of this method, two particle depolarization ratio measurement cases in Litang and Naqu are provided. The investigations 
on the polarizing properties of the aerosol and clouds over the Tibetan Plateau are provided. The cloud phases, spherical particles and nonspherical particles are identified by using depolarization ratios.

(4) During TIPEX III in Naqu, all the measurement cases of cirrus clouds are presented. In total, 21 separate cirrus clouds are found and the particle depolarization ratio, cirrus cloud base/top heights and cirrus middle height are retrieved. According to the results, the particle depolarization ratio of cirrus clouds differs from 0.36 to 0.52 , with a mean value of $0.44 \pm 0.04$. Cirrus clouds occurred between $5.2 \mathrm{~km}$ and $12 \mathrm{~km}$ a.g.l. The cloud thickness ranges from 0.12 to $2.55 \mathrm{~km}$ with a mean thickness of $1.22 \pm 0.70 \mathrm{~km}$. The occurrence frequencies of cirrus cloud base/top/middle heights are provided as well. Finally, the correlation between cirrus middle height and particle depolarization ratio is studied. It indicates that the particle depolarization ratio of cirrus clouds increases with the increasing height. While the increase rate of particle depolarization ratio decreases as the height increases.

Acknowledgments: This work was jointly supported by the National Key Research and Development Program of China under grant 2016YFC1400904, the National Natural Science Foundation of China (NSFC) under grant 41375016, 41471309 and 91337103, and the China Special Fund for Research in the Public Interest under grant GYHY201406001. The authors wish to thank Liping Liu, from CAMS/LAWS for his help and support before and during the observations. Thanks to the whole Lidar group of Ocean University of China. The authors would like to thank Julian Hofer from Leibniz Institute for Tropospheric Research, Germany for his kind help in editing the language.

Author Contributions: In this paper, all authors contributed to the paper concept and discussion of the methodology. Guangyao Dai dealt with the experiments and wrote the paper. Songhua Wu and Xiaoquan Song checked the data quality and polished the English language in this paper.

Conflicts of Interest: The authors declare no conflict of interest.

\section{References}

1. Sassen, K. The polarization lidar technique for cloud research: A review and current assessment. Bull. Am. Meteorol. Soc. 1991, 72, 1848-1866. [CrossRef]

2. Sassen, K. Polarization in lidar. In Lidar: Range-Resolved Optical Remote Sensing of the Atmosphere, 1st ed.; Weitkamp, C., Ed.; Springer: New York, NY, USA, 2005; Volume 102, pp. $19-42$.

3. Murayama, T.; Furushima, M.; Oda, A.; Iwasaka, N.; Kai, K. Depolarization ratio measurements in the atmospheric boundary layer by Lidar in Tokyo. J. Meteorol. Soc. Jpn. 1996, 74, 571-578. [CrossRef]

4. Gobbi, G.P. Polarization lidar returns from aerosols and thin clouds: A framework for the analysis. Appl. Opt. 1998, 37, 5505-5508. [CrossRef] [PubMed]

5. Sassen, K.; Zhu, J.; Webley, P.; Dean, K.; Cobb, P. Volcanic ash plume identification using polarization lidar: Augustine eruption, Alaska. Geophys. Res. Lett. 2007, 34, 162-179. [CrossRef]

6. Ansmann, A.; Mattis, I.; Müller, D.; Wandinger, U.; Radlach, M.; Althausen, D.; Damoah, R. Ice formation in saharan dust over central europe observed with temperature/humidity/aerosol Raman Lidar. J. Geophys. Res. Atmos. 2005, 110. [CrossRef]

7. Ansmann, A.; Tesche, M.; Althausen, D.; Müller, D.; Seifert, P.; Freudenthaler, V.; Heese, B.; Wiegner, M.; Pisani, G.; Knippertz, P. Influence of saharan dust on cloud glaciation in southern morocco during the saharan mineral dust experiment. J. Geophys. Res. Atmos. 2008, 113, 84. [CrossRef]

8. Gayet, J.F.; Stachlewska, I.S.; Jourdan, O.; Shcherbakov, V.; Schwarzenboeck, A.; Neuber, R. Microphysical and optical properties of precipitating drizzle and ice particles obtained from alternated lidar and in situ measurements. Ann. Geophys. 2007, 25, 1487-1497. [CrossRef]

9. Sassen, K.; Benson, S. A midlatitude cirrus cloud climatology from the facility for atmospheric remote sensing. Part II: Microphysical properties derived from lidar depolarization. J. Atmos. Sci. 2001, 58, 2103-2112. [CrossRef]

10. Chen, W.-N.; Chiang, C.-W.; Nee, J.-B. Lidar ratio and depolarization ratio for cirrus clouds. Appl. Opt. 2002, 41, 6470-6476. [CrossRef] [PubMed]

11. Sunilkumar, S.; Parameswaran, K. Temperature dependence of tropical cirrus properties and radiative effects. J. Geophys. Res. Atmos. 2005, 110. [CrossRef] 
12. Cairo, F.; Di Donfrancesco, G.; Adriani, A.; Pulvirenti, L.; Fierli, F. Comparison of various linear depolarization parameters measured by lidar. Appl. Opt. 1999, 38, 4425-4432. [CrossRef] [PubMed]

13. Sugimoto, N.; Nishizawa, T.; Shimizu, A.; Matsui, I.; Jin, Y. Characterization of aerosols in east Asia with the Asian dust and aerosol Lidar observation network (AD-net). In Proceedings of the Lidar Remote Sensing for Environmental Monitoring XIV, Beijing, China, 14-15 October 2014; International Society for Optics and Photonics: Bellingham, WA, USA, 2014; p. 92620K.

14. Janicka, L.; Stachlewska, I.S.; Veselovskii, I.; Baars, H. Temporal variations in optical and microphysical properties of mineral dust and biomass burning aerosol derived from daytime raman lidar observations over warsaw, poland. Atmos. Environ. 2017, 169, 162-174. [CrossRef]

15. Gobbi, G.P.; Barnaba, F.; Giorgi, R.; Santacasa, A. Altitude-resolved properties of a saharan dust event over the mediterranean. Atmos. Environ. 2000, 34, 5119-5127. [CrossRef]

16. Sakai, T.; Shibata, T.; Iwasaka, Y.; Nagai, T.; Nakazato, M.; Matsumura, T.; Ichiki, A.; Kim, Y.-S.; Tamura, K.; Troshkin, D. Case study of raman lidar measurements of asian dust events in 2000 and 2001 at nagoya and tsukuba, japan. Atmos. Environ. 2002, 36, 5479-5489. [CrossRef]

17. Murayama, T.; Müller, D.; Wada, K.; Shimizu, A.; Sekiguchi, M.; Tsukamoto, T. Characterization of asian dust and siberian smoke with multi-wavelength raman lidar over Tokyo, Japan in spring 2003. Geophys. Res. Lett. 2004, 31, 197-236. [CrossRef]

18. Sugimoto, N.; Matsui, I.; Shimizu, A.; Uno, I.; Asai, K.; Endoh, T.; Nakajima, T. Observation of dust and anthropogenic aerosol plumes in the northwest pacific with a two-wavelength polarization lidar on board the research vessel Mirai. Geophys. Res. Lett. 2002, 29. [CrossRef]

19. Groß, S.; Freudenthaler, V.; Schepanski, K.; Toledano, C.; Schäfler, A.; Ansmann, A.; Weinzierl, B. Optical properties of long-range transported saharan dust over barbados as measured by dual-wavelength depolarization raman lidar measurements. Atmos. Chem. Phys. 2015, 15, 11067-11080. [CrossRef]

20. Burton, S.; Hair, J.; Kahnert, M.; Ferrare, R.; Hostetler, C.; Cook, A.; Harper, D.; Berkoff, T.; Seaman, S.; Collins, J. Observations of the spectral dependence of linear particle depolarization ratio of aerosols using nasa langley airborne high spectral resolution lidar. Atmos. Chem. Phys. 2015, 15, 13453-13473. [CrossRef]

21. Haarig, M.; Ansmann, A.; Althausen, D.; Klepel, A.; Groß, S.; Freudenthaler, V.; Toledano, C.; Mamouri, R.-E.; Farrell, D.A.; Prescod, D.A. Triple-wavelength depolarization-ratio profiling of saharan dust over barbados during Saltrace in 2013 and 2014. Atmos. Chem. Phys. 2017, 17, 10767. [CrossRef]

22. Sugimoto, N.; Uno, I.; Nishikawa, M.; Shimizu, A.; Matsui, I.; Dong, X.; Chen, Y.; Quan, H. Record heavy Asian dust in Beijing in 2002: Observations and model analysis of recent events. Geophys. Res. Lett. 2003, 30, 1640. [CrossRef]

23. Groß, S.; Tesche, M.; Freudenthaler, V.; Toledano, C.; Wiegner, M.; Ansmann, A.; Althausen, D.; Seefeldner, M. Characterization of saharan dust, marine aerosols and mixtures of biomass-burning aerosols and dust by means of multi-wavelength depolarization and raman lidar measurements during samum 2. Tellus B 2011, 63, 706-724. [CrossRef]

24. Burton, S.; Ferrare, R.; Hostetler, C.; Hair, J.; Rogers, R.; Obland, M.; Butler, C.; Cook, A.; Harper, D.; Froyd, K. Aerosol classification using airborne high spectral resolution lidar measurements-methodology and examples. Atmos. Meas. Tech. 2012, 5, 73. [CrossRef]

25. Baars, H.; Kanitz, T.; Engelmann, R.; Althausen, D.; Heese, B.; Komppula, M.; Preißler, J.; Tesche, M.; Ansmann, A.; Wandinger, U. An overview of the first decade of polly net: An emerging network of automated raman-polarization lidars for continuous aerosol profiling. Atmos. Chem. Phys. 2016, 16, 5111-5137. [CrossRef]

26. Winker, D.M.; Vaughan, M.A.; Omar, A.; Hu, Y.; Powell, K.A.; Liu, Z.; Hunt, W.H.; Young, S.A. Overview of the calipso mission and caliop data processing algorithms. J. Atmos. Ocean. Technol. 2009, 26, 2310-2323. [CrossRef]

27. Hayashida, S.; Kobayashi, A.; Iwasaka, Y. Lidar measurements of stratospheric aerosol content and depolarization ratios after the eruption of el chichon volcano: Measurements at Nagoya, Japan. Geofis. Int. 1984, 23, 277-288.

28. Freudenthaler, V.; Esselborn, M.; Wiegner, M.; Heese, B.; Tesche, M.; Ansmann, A.; Müller, D.; Althausen, D.; Wirth, M.; Fix, A. Depolarization ratio profiling at several wavelengths in pure Saharan dust during SAMUM 2006. Tellus B 2009, 61, 165-179. [CrossRef] 
29. Browell, E.; Butler, C.; Ismail, S.; Robinette, P.; Carter, A.; Higdon, N.; Toon, O.; Schoeberl, M.; Tuck, A. Airborne lidar observations in the wintertime arctic stratosphere: Polar stratospheric clouds. Geophys. Res. Lett. 1990, 17, 385-388. [CrossRef]

30. Murayama, T.; Okamoto, H.; Kaneyasu, N.; Kamataki, H.; Miura, K. Application of lidar depolarization measurement in the atmospheric boundary layer: Effects of dust and sea-salt particles. J. Geophys. Res. Atmos. 1999, 104, 31781-31792. [CrossRef]

31. Reichardt, J.; Tsias, A.; Behrendt, A. Optical properties of psc ia-enhanced at uv and visible wavelengths: Model and observations. Geophys. Res. Lett. 2000, 27, 201-204. [CrossRef]

32. Behrendt, A.; Nakamura, T. Calculation of the calibration constant of polarization lidar and its dependency on atmospheric temperature. Opt. Express 2002, 10, 805-817. [CrossRef] [PubMed]

33. Reichardt, J.; Baumgart, R.; McGee, T.J. Three-signal method for accurate measurements of depolarization ratio with lidar. Appl. Opt. 2003, 42, 4909-4913. [CrossRef] [PubMed]

34. Alvarez, J.; Vaughan, M.A.; Hostetler, C.A.; Hunt, W.; Winker, D.M. Calibration technique for polarization-sensitive lidars. J. Atmos. Ocean. Technol. 2006, 23, 683-699. [CrossRef]

35. Freudenthaler, V. About the effects of polarising optics on lidar signals and the $\Delta 90$ calibration. Atmos. Meas. Tech. 2016, 9, 4181-4255. [CrossRef]

36. Bravo-Aranda, J.A.; Belegante, L.; Freudenthaler, V.; Alados-Arboledas, L.; Nicolae, D.; Granados-Muñoz, M.J.; Guerrero-Rascado, J.L.; Amodeo, A.; D’Amico, G.; Engelmann, R. Assessment of lidar depolarization uncertainty by means of a polarimetric lidar simulator. Atmos. Meas. Tech. 2016, 9, 4935. [CrossRef]

37. Kuwagata, T.; Numaguti, A.; Endo, N. Diurnal variation of water vapor over the central tibetan plateau during summer. J. Meteorol. Soc. Jpn. 2001, 79, 401-418. [CrossRef]

38. Wu, S.; Song, X.; Liu, B.; Dai, G.; Liu, J.; Zhang, K.; Qin, S.; Hua, D.; Gao, F.; Liu, L. Mobile multi-wavelength polarization raman lidar for water vapor, cloud and aerosol measurement. Opt. Express 2015, 23, 33870-33892. [CrossRef] [PubMed]

39. Fernald, F.G. Analysis of atmospheric lidar observations: Some comments. Appl. Opt. 1984, 23, 652-653. [CrossRef] [PubMed]

40. Klett, J.D. Lidar inversion with variable backscatter/extinction ratios. Appl. Opt. 1985, 24, 1638-1643. [CrossRef] [PubMed]

41. Bevington, P.R.; Robinson, D.K.; Blair, J.M.; Mallinckrodt, A.J.; McKay, S. Data reduction and error analysis for the physical sciences. Comput. Phys. 1993, 7, 415-416. [CrossRef]

42. Liou, K.-N. Influence of cirrus clouds on weather and climate processes: A global perspective. Mon. Weather Rev. 1986, 114, 1167-1199. [CrossRef]

(C) 2018 by the authors. Licensee MDPI, Basel, Switzerland. This article is an open access article distributed under the terms and conditions of the Creative Commons Attribution (CC BY) license (http://creativecommons.org/licenses/by/4.0/). 